\title{
Multi-body Dynamic Modelling and Error Analysis of Planar Flexible Multilink Mechanism Considering Clearance and Thermal-mechanical Coupling Effect of the Crankshaft-bearing Structure
}

Hongfan Long

Nanjing Agricultural University

Zhao Han

Nanjing Agricultural University

Shuyun Jiang

Southeast University

Enlai Zheng ( $\square$ EnlaiZheng@njau.edu.cn )

Nanjing Agricultural University https://orcid.org/0000-0003-1622-7608

Yongnian Zhang

Nanjing Agricultural University

Yue Zhu

Nanjing Agricultural University

Yongjian Wang

Nanjing Agricultural University

\section{Research Article}

Keywords: Thermal network, Clearance, Flexible, Thermal-mechanical coupling, Bottom dead point

Posted Date: September 2nd, 2021

DOl: https://doi.org/10.21203/rs.3.rs-833535/v1

License: (a) (i) This work is licensed under a Creative Commons Attribution 4.0 International License. Read Full License 


\title{
Multi-body dynamic modelling and error analysis of planar flexible multilink mechanism considering clearance and thermal-mechanical coupling effect of the crankshaft-bearing structure
}

\author{
Hongfan Long a , Zhao Han ${ }^{\text {a }}$, Shuyun Jiang ${ }^{\text {b }}$, Enlai Zheng a, *, Yongnian Zhang a \\ Yue Zhu ${ }^{\text {a, }}$ Yongjian Wang a \\ ${ }^{a}$ College of Engineering, Nanjing Agricultural University, Nanjing 210031, \\ China \\ ${ }^{b}$ School of Mechanical Engineering, Southeast University, Nanjing 211189, \\ China \\ Phone: +86 1345188 8670, Fax: 025-58606623, Email: EnlaiZheng@ njau.edu.cn
}

\begin{abstract}
In order to study the dynamic position accuracy of bottom dead point (BDP) for multilink high-speed precision presses (MHSPPs), it's essential to develop a dynamic model of planar multilink mechanism with clearance and spindle-bearing structure. Traditional models always neglect the effect of thermal characteristics of spindle-bearing structure, which reduces the prediction accuracy of dynamic model for multilink transmission mechanisms. To overcome the shortcomings of the previous models, a thermal network model (TNM) of the crankshaft-bearing system is established firstly considering the effects of thermal contact resistance and variable stiffness of bearing concerning the temperature rise. Then, dynamic model of the crankshaftbearing system is built through the finite element method, which includes rigid disk, Timoshenko beam and quasi-statics model of ACBB. On this basis, an improved dynamic model of planar flexible multilink mechanism with clearance considering the thermal-mechanical coupling effect of the crankshaft-bearing structure is developed and the corresponding dynamic error dimension chain between slider and crankshaft is constructed in this work. Compared to the simulation from traditional models, the simulated slider's BPD position error from the improved model agrees better with experimental data, which verifies the correctness of the proposed model. It's demonstrated that the punching force and thermally induced variable stiffness of bearing lead to a significant increase of slider's BDP position error, which reduces the machining precision of MHSPP. Furthermore, the influence of crankshaft speed, contact angle of bearing and clearance size on the slider's BDP position error is also investigated.
\end{abstract}

Keywords: Thermal network; Clearance; Flexible; Thermal-mechanical coupling; Bottom dead point

\section{Introduction}


When the press operates under high-speed punching conditions, flexible spindle structure and variable stiffness of bearing cause vibration error between ideal and actual axis trajectory, which affects the machining accuracy and its stability seriously. Meanwhile, temperature rise and thermal expansion due to heat generation of bearings lead to reduction of relative position accuracy between upper and lower molds. Therefore, it's necessary to develop the dynamic model of planar flexible multilink mechanism considering thermal-mechanical coupling effect of rotor-bearing structure to study the dynamic error of bottom dead point (BDP) position for multilink high-speed precision presses (MHSPPs).

To study the transmission error of multilink mechanism, it's key to model the clearance of revolute joints and flexibility of components. According to the relative motion state between bushing and pin, models of revolute joints can be classified as one-state (continuous contact), twostate (contact-separation) and three-state (collision-contact-separation), which have been widely used in the dynamic analysis of mechanism [1-6]. To simplify the numerical calculation, a continuous contact force model combining Hertzian elastic contact component with energy dissipation is presented to describe the collision/contact state uniformly [7], such as LankaraniNikravesh model [8], Flores model [9] and Hu-Guo model [10]. It's noteworthy that one-state model is simple but with largest error, inversely the most complex three-state model has the highest accuracy. Furthermore, the elastic foundation model (EFM) [11] and finite element model (FEM) [12] have also been proposed to improve the predictive precision of contact pressure between two joint elements.

The presence of friction phenomena during motion between bushing and pin affects the dynamic characteristics of mechanism significantly. To simulate the phenomena of sliding friction, viscous slip, viscous friction and Stribeck between pin and bushing in the revolute clearance joint, static and dynamic friction models are formed [13]. Static friction models are mainly used to describe the steady-state behaviour of friction force, while dynamic friction models are applied to capture the dynamic characteristics using additional state variables. As a typical representative of the static friction model, the Coulomb friction model has such problems as zero velocity discontinuity and strong nonlinearity, and needs to be modified to obtain stable numerical results $[14,15]$. In order to overcome the shortcomings of static friction models in capturing friction phenomena such as pre-sliding displacement or friction hysteresis, dynamic friction models based on "state variables", such as Dahl model [16], bristle model [17] and LuGre model [18], etc, are developed to study the dynamic characteristics of mechanism.

Compared with clearance of revolute joints, elastic deformation of components has more significant impact on transmission accuracy of mechanism. FEM is mainly used to model the flexible components in order to study the dynamic characteristics of mechanism. Based on FEM and absolute node coordinate method (ANCF), Wang et al. $[19,20]$ studied the dynamic response of flexible slider-crank mechanism with clearance and proposed an improved delayed feedback control strategy to stabilize its chaotic motion. Wang and Liu established a dynamic model of flexible five-bar linkage mechanism with clearance, and studied the influence of flexibility and clearance on its dynamic performance [21]. The authors also established the dynamic models of flexible slider-crank and multilink mechanism with clearance to investigate the influence of 
clearance and flexibility on the working accuracy of mechanism [22-24].

The existing methods for modelling and dynamic analysis of the spindle-bearing structure for machine tools are composed of the transfer matrix method (TMM) and FEM. The matrix order based on TMM won't rise with the increase of system's degree of freedom, which has been applied to model the spindle-bearing system. Aleyaasin et al. [25] established the flexural vibration model of a rotor-bearing system and deduced the general formula of system's tridiagonal division matrix through TMM to determine the unreasonable factors of model. Based on the concept of continuous system, Hsieh et al. [26] analyzed the coupled lateral and torsional vibrations of a symmetrical rotor-bearing system using TMM. Jiang and Zheng built a dynamic model of high-speed electric spindle system and analyzed the critical speed and dynamic stiffness characteristics of system [27, 28]. When TMM is used to compute high-order complex rotor systems, it's easy to cause the problems of numerical instability and "leakage roots". One solution is proposed to overcome the shortcomings of TMM above, which uses FEM to deal with complex rotor coupling systems considering the effect of surrounding structure. Ruhl [29] developed a FM model of spindle rotor system with translational inertia and bending stiffness of bearings considered to predict its stability and unbalanced responses, which neglects the effect of rotational inertia, gyroscopic moment, shear deformation, axial load, axial torque, and internal damping. Based on five-degree-of-freedom model of bearings and rigid shaft model, Aini [30] analyzed the dynamic characteristics of the spindle system supported by a pair of angular contact ball bearings (ACBBs). Considering the effect of radial clearance of rolling bearings and ball-race contact, Sinou [31] developed a FM model of flexible spindle supported by ball bearings and analyzed its nonlinear unbalanced response and rotor trajectory. When bearing is regarded as linear spring, Nelson [32] developed a dynamics model of the spindle system for machine tools, which considers the effect of rotational inertia, gyroscopic moment, shear deformation and axial load. Wang et al. [33] established a vibration model of the spindle-bearing structure for crank press system and analyzed its vibration characteristics.

In the process of operating the spindle system, the thermal error caused by the heating of the bearing and other components cannot be ignored. Thermal analysis methods of the spindle rotorbearing system can be currently divided into two types: thermal network method (TNM) and FEM. TNM has the advantages of small computation and is widely applied to predict the temperature field distribution of the spindle system. With lubrication and assembly form of bearings considered, Chen et al. [34] constructed a TN model of a spindle rotor-bearing system through seven-node element to investigate the influence of thermal deformation on contact angel of ball bearings. Compared with the TNM, FEM has higher analysis precision and can handle complex structures. Yan et al. [35] proposed a multi-objective optimization method to determine the optimized thermal model parameters of rolling bearings. Zhang et al. [36] established a thermal FE model of ball bearings considering uniform or non-uniform preload to predict its temperature field distribution. When thermal contact resistance and heat generation variation with respect to bearing temperature rise are considered, Zheng et al. [37] developed a FE thermal model of the high-speed precision presses and predicted its temperature rise and thermal-induced error. Furthermore, considering the effect of linkage flexibility and lubricating oil on heat generation of bearings, 
Zheng et al. [38, 39] studied the temperature field and thermal deformation variation law of the crankshaft-rotor-bearing system for MHSPP through FEM.

There have been several publications on thermal-mechanical coupling characteristics analysis of the spindle-bearing system. Liu et al. [40] and Zehadi et al. [41] established a thermal model of the spindle-bearing system and analyzed its thermal-mechanical coupling characteristics. Considering the influence of thermal deformation of bearings and spindle on the geometric change of bearings, Lai et al. [42] developed a thermal-mechanical coupling model of electric spindle system for machine tools. With the effect of thermal radial and centrifugal expansion on bearing stiffness considered, Truong et al. [43] studied the thermal-mechanical coupling dynamic response of the spindle-bearing system. Ma et al. [44] built a thermal-mechanical coupling threedimensional FE model of the electric spindle system and analyzed its temperature field and thermal deformation changes considering the comprehensive effect of thermal contact resistance and bearing stiffness. Based on the quasi-static model and FEM, Than et al. [45] constructed a thermal-mechanical coupling model of the spindle-bearing system, and studied the nonlinear characteristics of preload and bearing stiffness with respect to temperature change.

The existing models only consider the factors of revolute clearance joints, linkage flexibility and spindle-bearing structure dynamic, neglecting the effect of thermal characteristics of rotorbearing structure, which reduces the prediction accuracy of dynamic model for multilink mechanism of MHSPP. In this work, an improved dynamic model of planar flexible multilink mechanism considering clearance and thermal-mechanical coupling effect of rotor-bearing structure is developed and the corresponding dynamic error dimension chain between slider and crankshaft is constructed. The correctness of the proposed improved model is verified through comparison between simulation and experiment. Furthermore, the influence of crankshaft speed, contact angle of bearing and clearance size on slider's BDP position error is also investigated.

\section{Traditional model of multilink mechanism with crankshaft-bearing structure}

The solid model of the multilink mechanism for MHSPP is shown in Fig. 1. The mechanism is composed of the crankshaft-bearing structure and toggle mechanism in series. When crank shaft 2 rotates around point $\mathrm{O}$, slider 4 is driven to execute reciprocating motion from left to right along the guide rail through connecting rod 3. Pendulum rods 5 and 6 are hinged with slider 4, which forces lower and upper sliders $(7,8)$ to move back and forth in the vertical direction.

The dynamic accuracy of the MHSPP is mainly determined by the BDP position accuracy of lower slider 7. In order to predict and evaluate the performance of MHSPP, a dynamic model of planar flexible multilink mechanism with clearance and crankshaft-bearing structure is established, as shown in Fig. 2. The deformation of pendulum rod 6 due to the punching force between upper and lower moulds, gravity and inertia force of slider 7 is very significant and the flexibility of pendulum rod 6 and imperfect revolute joint between slider 7 and pendulum rod 6 are considered in this work. Furthermore, the effect of clearance between crank shaft 2 and connecting rod 3, and flexibility of crank shaft is also considered. 


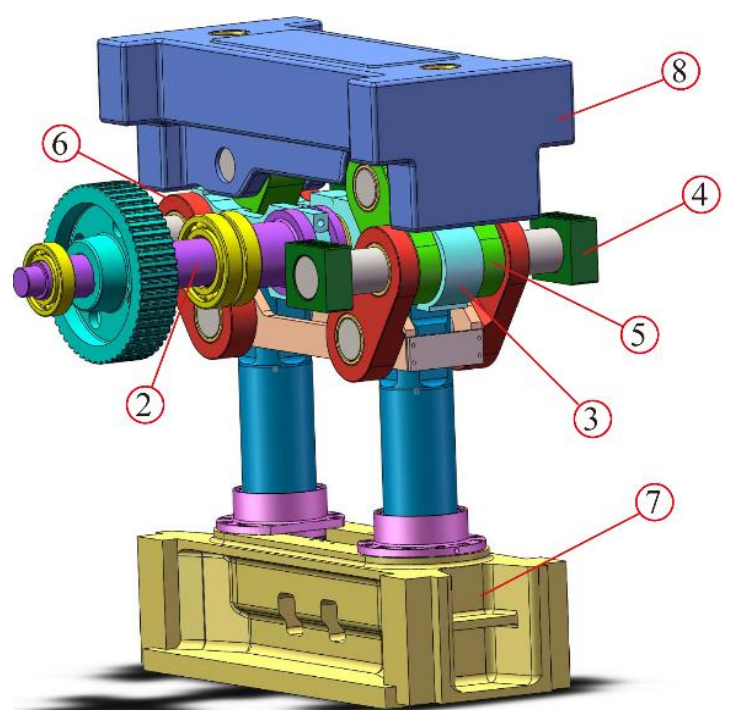

Fig.1 Solid model of multilink mechanism

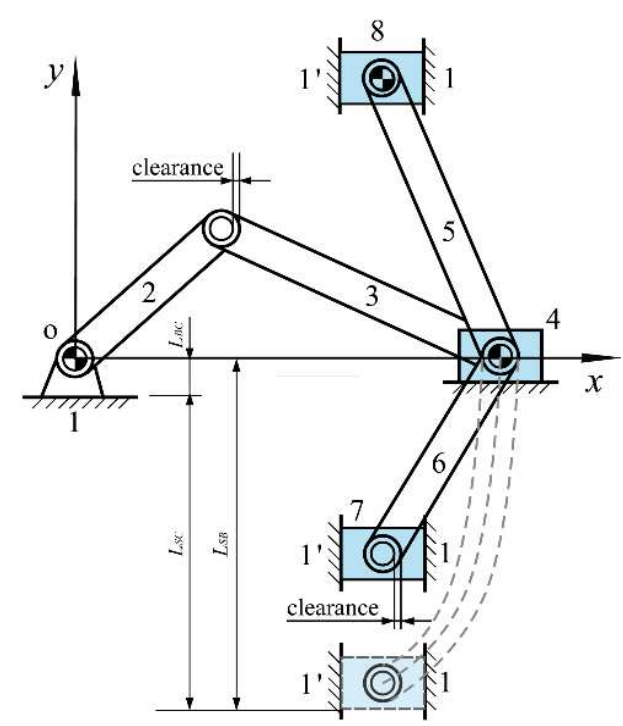

Fig.2 Multibody dynamic model of multilink mechanism

\subsection{Model of revolute clearance joint}

The centre of the pin coincides with that of the bushing in the ideal joint and only relative rotation occurs between the bushing and pin. In the actual revolute joint, there exists clearance between the pin and the bushing, which causes the centre deviation between two joint elements. When the pin keeps contact with the bushing, it produces impact and the corresponding contact force. The model of revolute clearance joint is shown in Fig. 3 and the eccentricity vector that connects the pin and bushing centre can be given by

$$
\mathbf{e}_{1}=\mathbf{r}_{\mathbf{i}}^{\mathbf{p}}-\mathbf{r}_{\mathbf{j}}^{\mathbf{p}}=\left(\mathbf{r}_{\mathbf{i}}+\mathbf{A}_{\mathbf{i}} \mathbf{s}_{\mathbf{i}}^{\prime}\right)-\left(\mathbf{r}_{\mathbf{j}}+\mathbf{A}_{\mathbf{j}} \mathbf{s}_{j}^{\prime}\right)
$$

Where $\mathbf{r}_{\mathbf{i}}$ and $\mathbf{r}_{\mathbf{j}}$ represent the vectors of the mass centre for bodies $i$ and $j$ in global coordinate system, $\mathbf{s}_{\mathbf{i}}^{\prime}$ and $\mathbf{s}_{j}^{\prime}$ are the position vectors of pin and bushing centre in local coordinate system, $\mathbf{A}_{\mathbf{i}}$ and $\mathbf{A}_{\mathbf{j}}$ are the transformation matrix vectors from local to global coordinate system.

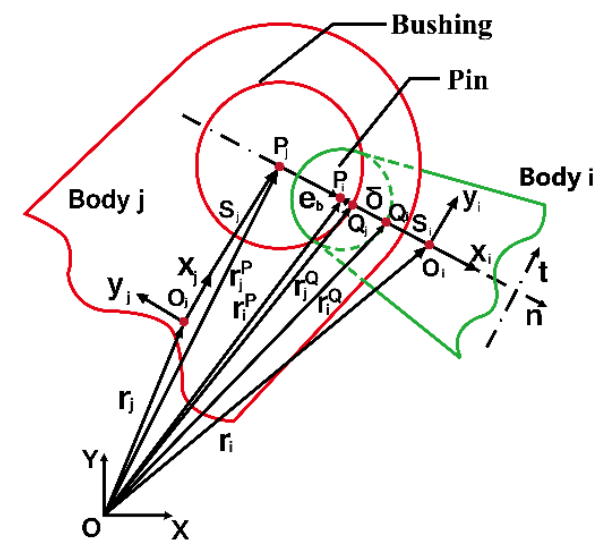

Fig.3 Model of revolute clearance joint

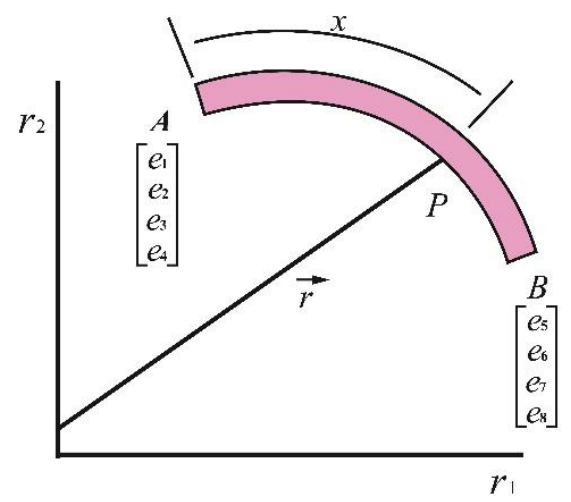

Fig.4 Model of flexible linkage

The unit vector along the direction of the eccentricity vector can be expressed as

$$
\mathbf{n}=\mathbf{e}_{1} /\left\|\mathbf{e}_{1}\right\|
$$

The position vector of the contact point between the pin and bushing in the global coordinate 
system can be expressed as

$$
\mathbf{r}_{\mathbf{m}}^{\mathbf{Q}}=\mathbf{r}_{\mathbf{m}}+\mathbf{A}_{\mathbf{m}} \mathbf{s}_{\mathbf{m}}+R_{m} \mathbf{n},(m=i, j)
$$

Where $R_{m}$ represents the radius of the pin or bushing, $R_{i}=R_{P}, R_{j}=R_{B}$.

When the pin collides with the bushing, the penetration depth can be written as

$$
\delta=\left\|\mathbf{e}_{1}\right\|-c
$$

Where $c$ is the radius difference between the pin and bushing, $c=R_{B}-R_{P}$.

The relative contact velocity between the pin and bushing can be defined as

$$
\dot{\boldsymbol{\delta}}=\dot{\mathbf{r}}_{\mathbf{j}}^{\mathbf{Q}}-\dot{\mathbf{r}}_{\mathbf{i}}^{\mathbf{Q}}=v_{n} \mathbf{n}+v_{t} \mathbf{t}
$$

Where $v_{n}$ and $v_{t}$ are the normal and tangential velocities of the contact point, respectively.

The angle between the eccentricity and the horizontal directions can be given by

$$
\alpha=\arctan \left(e_{1 x} / e_{1 y}\right)
$$

When the penetration depth is less than zero, contact force will disappear between the pin and bushing. On the contrary, contact force generates between two joint elements. According to the contact force model proposed by Lankarani and Nikravesh, the contact force can be divided into elastic and dissipative components [8]. Based on the Hertz contact theory, the contact force model combining with the hysteresis damping function can be defined as

$$
F_{n}=K_{n} \delta^{n}+D_{n} \dot{\delta}
$$

The contact stiffness coefficient $K_{n}$ can be expressed as

$$
K_{n}=\frac{4 \sqrt{\left(R_{B} R_{P}\right) /\left(R_{B}+R_{P}\right)}}{3 \pi\left(\left(1-\mu_{B}\right) /\left(\pi E_{B}\right)+\left(1-\mu_{P}\right) /\left(\pi E_{P}\right)\right)}
$$

The damping coefficient $D_{n}$ can be given by

$$
D_{n}=3 K_{n}\left(1-c_{e}\right) \delta^{n} / 4 \dot{\delta}^{(-)}
$$

Where $c_{e}$ is the collision recovery coefficient, $\dot{\delta}^{(-)}$is the initial collision velocity before collision.

To overcome the numerical difficulties due to the saltation of friction force that results from the sudden change of tangential velocity, the Coulomb friction force is modified as $[14,15]$

$$
F_{t}=-c_{f} c_{d} F_{n}
$$

Where $c_{f}$ is the friction coefficient, $c_{d}$ is the dynamic correction factor.

The dynamic correction factor can be expressed as

$$
c_{d}=\left\{\begin{array}{cc}
0 & v_{t} \leq v_{l} \\
\left(v_{t}-v_{l}\right) /\left(v_{u}-v_{l}\right) & v_{l}<v_{t} \leq v_{u} \\
1 & v_{t}>v_{u}
\end{array}\right.
$$


Where $v_{u}$ and $v_{l}$ represent the given upper and lower limits of the relative tangential velocity between the pin and bushing.

The multi-body dynamic equation of rigid multilink mechanism can be given by

$$
\left[\begin{array}{cc}
\mathbf{M}^{r} & \boldsymbol{\Phi}_{\mathbf{q}}^{T} \\
\boldsymbol{\Phi}_{\mathbf{q}} & 0
\end{array}\right]\left[\begin{array}{c}
\ddot{\mathbf{q}} \\
\boldsymbol{\lambda}
\end{array}\right]=\left[\begin{array}{c}
\mathbf{F}^{\mathbf{r}} \\
\boldsymbol{\gamma}
\end{array}\right]
$$

Where $\mathbf{q}$ represents the configuration coordinate, $\mathbf{M}^{r}$ is the mass matrix with respect to the configuration coordinate, $\mathbf{F}^{\mathbf{r}}$ is the external force matrix, and $\lambda$ is the Lagrange multiplier, $\boldsymbol{\gamma}=-\left[\left(\boldsymbol{\Phi}_{\mathbf{q}} \dot{\mathbf{q}}\right)_{\mathbf{q}} \dot{\mathbf{q}}+\boldsymbol{\Phi}_{\mathbf{q} t} \dot{\mathbf{q}}+\boldsymbol{\Phi}_{t \mathbf{q}} \dot{\mathbf{q}}+\boldsymbol{\Phi}_{t t}\right], \mathbf{q}=\left[\begin{array}{lll}\mathbf{q}_{2}^{\mathbf{T}} & \cdots & \mathbf{q}_{\mathbf{8}}^{\mathbf{T}}\end{array}\right]^{T}, \mathbf{q}_{\mathbf{i}}=\left[\begin{array}{ll}\mathbf{r}_{\mathbf{i}}^{T} & \theta_{i}\end{array}\right]^{T}=\left[\begin{array}{lll}x_{i} & y_{i} & \theta_{i}\end{array}\right]^{T}, \theta_{i}$ is the rotation angle of part $i$,

$$
\begin{aligned}
& \boldsymbol{\Phi}_{\mathbf{q}}=\left[\begin{array}{ccc}
\frac{\partial \boldsymbol{\Phi}_{1}}{\partial \mathbf{q}_{1}} & \cdots & \frac{\partial \boldsymbol{\Phi}_{1}}{\partial \mathbf{q}_{21}} \\
\vdots & & \vdots \\
\frac{\partial \boldsymbol{\Phi}_{21}}{\partial \mathbf{q}_{1}} & \cdots & \frac{\partial \mathbf{\Phi}_{21}}{\partial \mathbf{q}_{21}}
\end{array}\right], \quad \boldsymbol{\Phi}_{t}=\left[\begin{array}{lll}
\frac{\partial \boldsymbol{\Phi}_{1}}{\partial t} & \cdots & \frac{\partial \boldsymbol{\Phi}_{21}}{\partial t}
\end{array}\right]^{T}, \quad \mathbf{M}^{\mathbf{r}}=\left[\begin{array}{cccc}
\mathbf{M}_{1}^{\mathrm{r}} & 0 & \cdots & 0 \\
0 & \mathbf{M}_{2}^{\mathbf{r}} & \cdots & 0 \\
\vdots & \vdots & & \vdots \\
0 & 0 & \cdots & \mathbf{M}_{\mathbf{n}}^{\mathbf{r}}
\end{array}\right], \\
& \mathbf{M}_{\mathbf{i}}^{\mathbf{r}}=\left[\begin{array}{ccc}
m_{i} & 0 & 0 \\
0 & m_{i} & 0 \\
0 & 0 & J_{i}
\end{array}\right], \quad \mathbf{F}^{\mathbf{r}}=\left[\begin{array}{c}
\mathbf{F}_{\mathbf{1}}^{\mathbf{r}} \\
\mathbf{F}_{\mathbf{2}}^{\mathbf{r}} \\
\vdots \\
\mathbf{F}_{\mathbf{n}}^{\mathbf{r}}
\end{array}\right], \quad \mathbf{F}_{\mathbf{i}}^{\mathbf{r}}=\left[\begin{array}{c}
0 \\
-m_{i} g \\
0
\end{array}\right]
\end{aligned}
$$

\subsection{Model of flexible linkage}

When the MHSPP operates, especially under punching condition, the influence of linkage's deformation on the dynamic accuracy of slider's BDP position cannot be ignored. The original rigid linkage must be described as a flexible model, as shown in Fig. 4. In this work, ANCF is used to establish the model of flexible linkage 6 and its dynamic equations can be given by

$$
\mathbf{M}^{f} \ddot{\mathbf{p}}+\mathbf{K}^{f} \mathbf{p}=\mathbf{Q}^{f}
$$

Where $\mathbf{p}=\left[\begin{array}{lll}e_{1} & \cdots & e_{4 n+4}\end{array}\right]^{T}, n$ is the number of linkage elements, $\mathbf{M}^{f}$ is the mass matrix of flexible linkage, $\mathbf{M}^{f}=\sum_{i=1}^{n} \mathbf{B}_{i}{ }^{T} \mathbf{M}_{i} \mathbf{B}_{i}, \mathbf{B}_{i}=\left[\begin{array}{lll}\mathbf{0}_{8 \times(4 i-4)} & \mathbf{E}_{8 \times 8} & \mathbf{0}_{8 \times(4 n-4 i)}\end{array}\right], \mathbf{M}_{\mathbf{i}}=\rho A l \int_{0}^{1} \mathbf{S}^{T} \mathbf{S} d \xi, \rho$ is the density of linkage, $A$ is the cross section area of linkage element, $l$ is the length of element, $\mathbf{K}^{f}$ is the stiffness matrix, $\mathbf{K}^{f}=\sum_{i=1}^{n} \mathbf{B}_{i}^{T} \mathbf{K}_{i} \mathbf{B}_{i}, \mathbf{K}_{i}=\mathbf{K}_{l}+\mathbf{K}_{t}, \mathbf{K}_{l}=\left(E A l \int_{0}^{1}\left(\mathbf{e}^{T} \mathbf{S}_{e l} \mathbf{e}\right) \mathbf{S}_{e l} d \xi-E A l \int_{0}^{1} \mathbf{S}_{e l} d \xi\right) / 2$, $\mathbf{e}=\left[\begin{array}{llllllll}e_{1} & e_{2} & e_{3} & e_{4} & e_{5} & e_{6} & e_{7} & e_{8}\end{array}\right]^{T}, e_{1}=\left.r_{1}\right|_{x=0}, e_{2}=\left.r_{2}\right|_{x=0}, e_{3}=\partial r_{1} /\left.\partial x\right|_{x=0}, e_{4}=\partial r_{2} /\left.\partial x\right|_{x=0}$, $e_{5}=\left.r_{1}\right|_{x=l}, e_{6}=\left.r_{2}\right|_{x=l}, e_{7}=\partial r_{1} /\left.\partial x\right|_{x=l}, e_{8}=\partial r_{2} /\left.\partial x\right|_{x=l}, r_{1}$ and $r_{2}$ are the horizontal and vertical components of position vector in the global coordinate system, $\mathbf{r}=\left[\begin{array}{ll}r_{1} & r_{2}\end{array}\right]^{T}=\mathbf{S e}, \overline{\mathbf{S}}_{l}=\int_{0}^{1} \mathbf{S}_{e l} d \xi$, $\mathbf{K}_{t}=E I \mathbf{S}_{t} / \overline{\mathbf{f}}^{4}-2 E I\left(\mathbf{e}^{T} \mathbf{S}_{t} \mathbf{e}\right) \overline{\mathbf{S}}_{l} / \overline{\mathbf{f}}^{6}, \mathbf{S}_{t}=l^{-3} \int_{0}^{1}\left[\partial^{2} \mathbf{S} / \partial \xi^{2}\right]^{T}\left[\partial^{2} \mathbf{S} / \partial \xi^{2}\right] d \xi, \mathbf{S}_{e l}=[\partial \mathbf{S} / \partial \xi]^{T}[\partial \mathbf{S} / \partial \xi] l^{-2}$, $s_{1}=1-3 \xi^{2}+2 \xi^{3}, s_{2}=\xi-2 \xi^{2}+\xi^{3}, s_{3}=3 \xi^{2}-2 \xi^{3}, s_{4}=\xi^{3}-\xi^{2}, \xi=x / l, x$ is the coordinate of 
point $P$ in the local coordinate system before deformation, $I$ denotes the diametral inertia moment of the linkage element, $\mathbf{Q}^{f}$ represents the generalized external force of the flexible linkage, $\mathbf{Q}^{f}=\sum_{i=1}^{n} \mathbf{B}_{i}^{T} \mathbf{Q}_{i}, \mathbf{Q}_{i}=A l \int_{0}^{1} \mathbf{S}^{T} \mathbf{f} d \xi, \mathbf{f}=\left[\begin{array}{ll}0 & -\rho g\end{array}\right]^{T}, \mathbf{S}=\left[\begin{array}{cccccccc}s_{1} & 0 & s_{2} l & 0 & s_{3} & 0 & s_{4} l & 0 \\ 0 & s_{1} & 0 & s_{2} l & 0 & s_{3} & 0 & s_{4} l\end{array}\right]$.

The multi-body dynamic equations of the planar flexible multilink mechanism with clearance can be expressed as

$$
\left[\begin{array}{cccc}
\mathbf{M}^{\mathrm{r}} & & \mathbf{0} & \\
& \mathbf{M}_{\mathrm{f}} & & \boldsymbol{\Phi}_{\mathbf{q}}^{\mathbf{T}} \\
\mathbf{0} & & \mathbf{M}_{7}^{\mathbf{r}} & \\
& \boldsymbol{\Phi}_{\mathrm{q}} & & \mathbf{0}
\end{array}\right]\left[\begin{array}{l}
\ddot{\mathbf{q}} \\
\boldsymbol{\lambda}
\end{array}\right]=\left[\begin{array}{c}
\mathbf{F}^{\mathbf{r}} \\
\mathbf{Q}^{\mathbf{f}} \\
\gamma
\end{array}\right]
$$

Where $\mathbf{M}^{\mathbf{r}}=\left[\begin{array}{lll}\mathbf{M}_{1}^{\mathbf{r}} & & \\ & \ddots & \\ & & \mathbf{M}_{5}^{\mathbf{r}}\end{array}\right], \quad \mathbf{q}=\left[\begin{array}{lllll}\mathbf{q}_{1}^{T} & \cdots & \mathbf{q}_{5}^{T} & \mathbf{p} & \mathbf{q}_{7}^{T}\end{array}\right]^{T}$.

\subsection{Model of the crankshaft-bearing system}

The structure of the crankshaft-bearing system for MHSPP is shown in Fig. 5, which is mainly composed of the crank shaft, ACBBs and synchronous pulley. The synchronous pulley, crankshaft and ACBB in the spindle system are modelled through the rigid disk, Timoshenko beam and spring element, respectively, and the FE model of the system is developed, as shown in Fig. 6. There are 23 shaft segments in the model. The $5^{\text {th }}$ shaft segment is a disk element, and the $13^{\text {th }}$ and $17^{\text {th }}$ shaft segments represent the eccentric parts of the crank shaft.

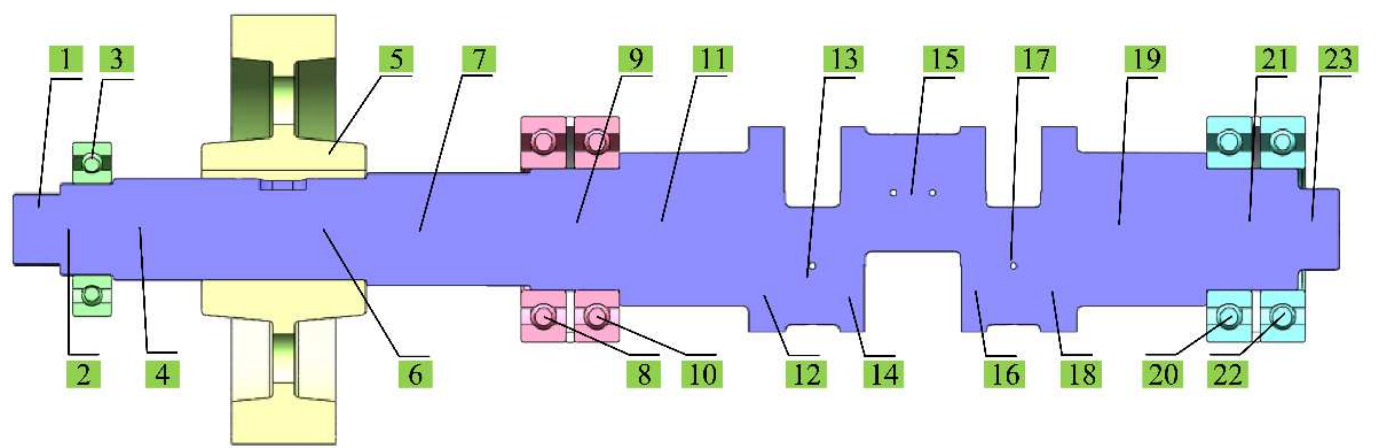

Fig.5 Structure of the crankshaft-bearing system for MHSPP

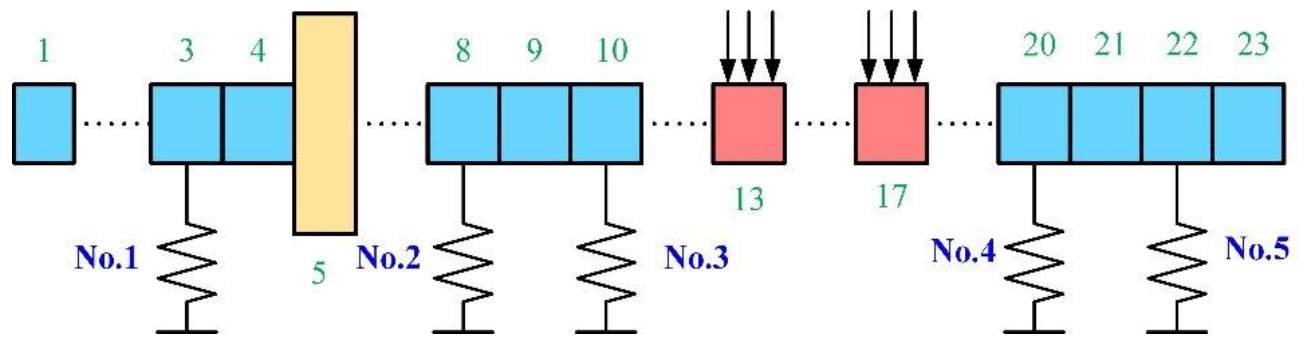

Fig.6 FE model of the crankshaft-bearing system

\section{(1) Model of the synchronous pulley}

The synchronous pulley is modelled using rigid disk element. It is assumed that the damping 
of the rigid disk can be neglected. Based on the Lagrangian method, the dynamic equations of the rigid disk can be expressed as [45]

$$
\left[\mathbf{M}^{d}\right]\left\{\ddot{\mathbf{q}}^{d}\right\}-\omega_{2}\left[\mathbf{G}^{d}\right]\left\{\dot{\mathbf{q}}^{d}\right\}=\left\{\mathbf{F}^{d}\right\}
$$

Where $\left[\mathbf{M}^{d}\right]$ represents the mass matrix of rigid disk, $\left[\mathbf{G}^{d}\right]$ is the gyroscopic matrix, $\left\{\mathbf{F}^{d}\right\}$ is the external force vector, $\left\{\mathbf{q}^{d}\right\}$ is the displacement vector.

\section{(2) Model of the crankshaft}

Each shaft section is modelled by Timoshenko elastic beam element. Based on the Hamilton principle, the dynamic equations of the beam element in the matrix form can be written as

$$
\left[\mathbf{M}^{b}\right]\left\{\ddot{\mathbf{q}}^{b}\right\}-\omega_{2}\left[\mathbf{G}^{b}\right]\left\{\dot{\mathbf{q}}^{b}\right\}+\left(\left[\mathbf{K}^{b}\right]+\left[\mathbf{K}^{b}\right]_{P}-\omega_{2}^{2}\left[\mathbf{M}^{b}\right]_{C}\right)\left\{\mathbf{q}^{b}\right\}=\left\{\mathbf{F}^{b}\right\}
$$

Where $\left[\mathbf{M}^{b}\right]$ represents the mass matrix of the beam element, $\left[\mathbf{M}^{b}\right]_{C}$ is the mass matrix relative to the centrifugal force, $\left[\mathbf{G}^{b}\right]$ is the gyroscopic matrix, $\left[\mathbf{K}^{b}\right]$ is the stiffness matrix, $\left[\mathbf{K}^{b}\right]_{P}$ is the stiffness matrix due to the axial load, $\left\{\mathbf{F}^{b}\right\}$ is the discrete and concentrated force vector.

\section{(3) Model of the ACBB}

The stiffness of ACBB has a significant impact on the dynamic responses of the crankshaftbearing system for MHSPP. It's necessary to establish a mathematical model of the ACBB to calculate its stiffness. As shown in Fig. 7, parameters $\delta_{x}, \delta_{y}, \delta_{z}, \gamma_{y}$ and $\gamma_{z}$ are used to describe the ACBB's displacement in the Cartesian coordinate system $O-x y z$. The angular position $\varphi_{k}$ of the $\mathrm{k}^{\text {th }}$ rolling element for ACBB under free state can be given by

$$
\varphi_{k}=2 \pi k / N
$$

Where $N$ is the number of rolling element for the ACBB.

The curvature centres of inner and outer raceways are initially coincided with the centre of rolling element. As shown in Fig. 8, the distance between curvature centres of inner and outer raceways can be calculated as

$$
B_{d}=B D=\left(f_{i}+f_{o}-1\right) D
$$

Where $D$ is the diameter of the rolling element.

When the press system operates, the external load acting on the ACBB will cause its contact angle $\theta$ to change. It is assumed that the outer raceway of ACBB is fixed and the distances between the curvature centre of the inner ring groove and the final position of the ball centre, between the curvature centre of the outer ring groove and the final position of the ball centre can be given by

$$
\Delta_{i k}=r_{i}-D / 2+\delta_{i k}=\left(f_{i}-0.5\right) D+\delta_{i k}
$$




$$
\Delta_{o k}=r_{o}-D / 2+\delta_{o k}=\left(f_{o}-0.5\right) D+\delta_{o k}
$$

Where $\delta_{i k}$ and $\delta_{o k}$ represent the deformation between inner raceway and the rolling element, between outer raceway and the rolling element.
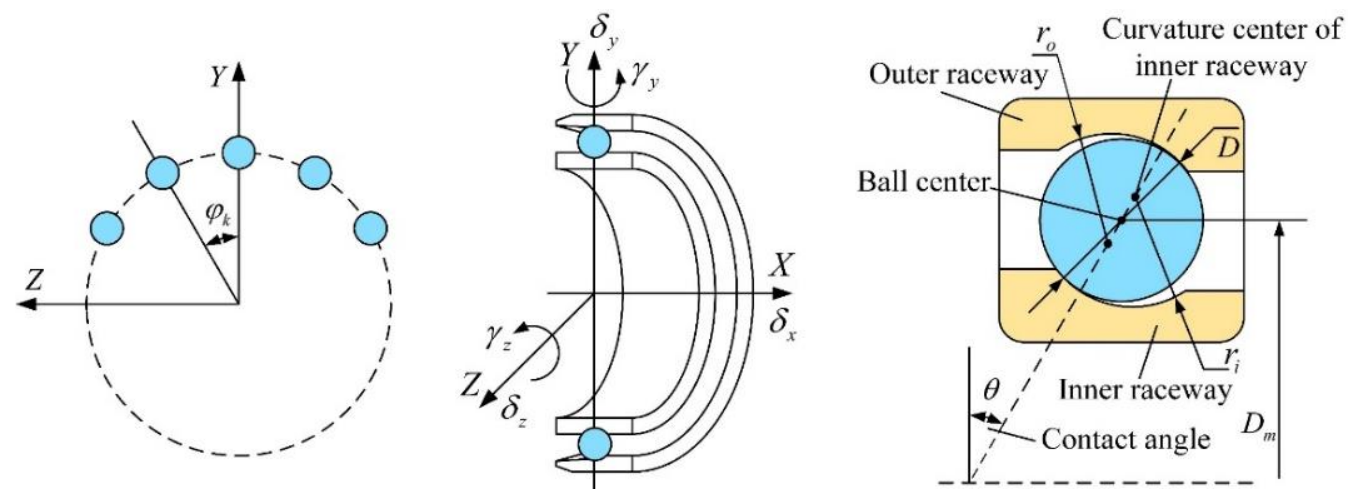

Fig.7 Geometry relationship of the ACBB
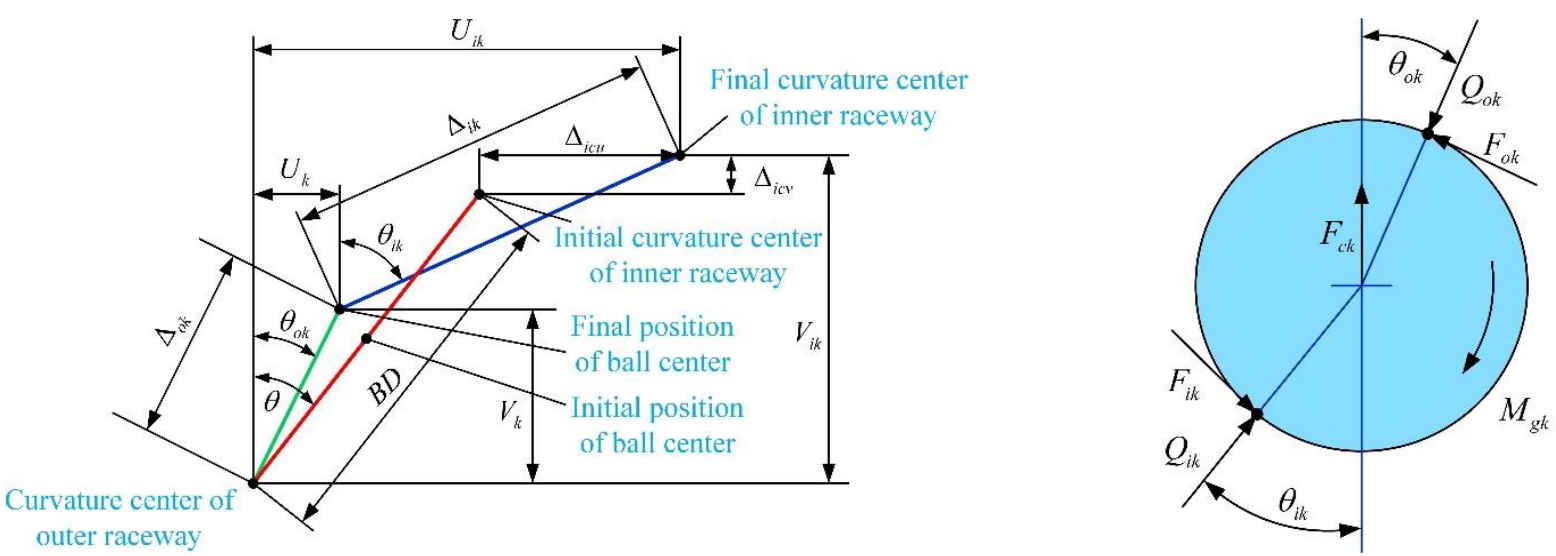

Fig.8 Displacement relationship between inner and outer curvature centres Fig.9 Force balance of rolling element Based on Pythagorean theorem, the position geometric equations of ACBB can be given by

$$
\begin{gathered}
\left(U_{i k}-U_{k}\right)^{2}+\left(V_{i k}-V_{k}\right)^{2}-\Delta_{i k}^{2}=0 \\
U_{k}^{2}+V_{k}^{2}-\Delta_{o k}^{2}=0
\end{gathered}
$$

Where $U_{i k}=B_{d} \sin \theta+\Delta \delta_{x}-\Delta \gamma_{z} r_{i c} \cos \varphi_{k}+\Delta \gamma_{y} r_{i c} \sin \varphi_{k}, V_{i k}=B_{d} \cos \theta+\Delta \delta_{y} \cos \varphi_{k}+\Delta \delta_{z} \sin \varphi_{k}$, $\Delta \delta_{x}, \Delta \delta_{y}, \Delta \delta_{z}, \Delta \gamma_{y}$ and $\Delta \gamma_{z}$ represent the relative displacements between inner and outer raceways of ACBB under external loads, $r_{i c}=D_{m} / 2+\left(f_{i}-0.5\right) D \cos \theta$. As shown in Fig. 9, the force balance equations of the rolling element can be given by

$$
\begin{gathered}
Q_{o k} \cos \theta_{o k}-\frac{M_{g k}}{D} \sin \theta_{o k}-Q_{i k} \cos \theta_{i k}+\frac{M_{g k}}{D} \sin \theta_{i k}-F_{c k}=0 \\
Q_{o k} \sin \theta_{o k}+\frac{M_{g k}}{D} \cos \theta_{o k}-Q_{i k} \sin \theta_{i k}-\frac{M_{g k}}{D} \cos \theta_{i k}=0
\end{gathered}
$$

Where $F_{c k}$ is the centrifugal force of the rolling element, $F_{c k}=m D_{m} \omega^{2}\left(\omega_{E} / \omega\right)_{k}^{2} / 2, m$ is the mass of the rolling element, $D_{m}$ is the middle diameter of ACBB, $\omega$ is the rotation speed of the 
crankshaft, $M_{g k}$ is the gyroscopic moment, $M_{g k}=J_{b} \omega^{2}\left(\omega_{B} / \omega\right)_{k}\left(\omega_{E} / \omega\right)_{k}^{2} \sin \alpha_{k}, J_{b}$ is the inertia moment of the rolling element, $\alpha_{k}=\arctan \left(\sin \theta_{i k} /\left(\cos \theta_{i k}-\lambda\right)\right), \theta_{i k}$ and $\theta_{o k}$ represent the contact angles of the inner and outer raceways, $Q_{i k}$ and $Q_{o k}$ are the contact forces of the inner and outer raceways, $\left.\theta_{i k}=\arcsin \left\{\left(U_{i k}-U_{k}\right) /\left[\left(f_{i}-0.5\right) D+\delta_{i k}\right]\right\}, \theta_{o k}=\arcsin \left\{U_{k} /\left[\left(f_{o}-0.5\right) D+\delta_{o k}\right)\right]\right\}$.

$\left(\omega_{B} / \omega\right)_{k}$ and $\left(\omega_{E} / \omega\right)_{k}$ can be calculated as

$$
\begin{aligned}
& \left(\omega_{B} / \omega\right)_{k}=-1 /\left\{\left[\left(\cos \theta_{o k}+\tan \alpha_{k} \sin \theta_{o k}\right) /\left(1+\lambda \cos \theta_{o k}\right)\right.\right. \\
& \left.+\left[\left(\cos \theta_{i k}+\tan \alpha_{k} \sin \alpha_{k} \sin \theta_{i k}\right) /\left(1-\lambda \cos \theta_{i k}\right)\right] \lambda \cos \alpha_{k}\right\} \\
& \left(\omega_{E} / \omega\right)_{k}=\left[\cos \left(\theta_{i k}-\theta_{o k}\right)-\lambda \cos \theta_{o k}\right] /\left[1+\cos \left(\theta_{i k}-\theta_{o k}\right)\right]
\end{aligned}
$$

Based on Hertz theorem, the contact forces $Q_{i k}$ and $Q_{o k}$ can be given by

$$
Q_{i k}=K_{i} \delta_{i k}^{3 / 2}, Q_{o k}=K_{o} \delta_{o k}^{3 / 2}
$$

Where $K_{i}$ and $K_{o}$ are the contact stiffness of the inner and outer raceways, which can be written as

$$
K=\pi k E^{\prime} \sqrt{2 E R / F} /(3 F)
$$

Where $k=1.0339\left(R_{x} / R_{y}\right)^{0.636}, E^{\prime}=2 /\left[\left(1-\mu_{a}^{2}\right) / E_{a}+\left(1-\mu_{b}^{2}\right) / E_{b}\right], F=1.5277+0.6023\left(R_{x} / R_{y}\right)$, $E=1.0003+0.5968\left(R_{x} / R_{y}\right)$.

When the inner raceway keeps in contact with the rolling element, $R_{x}$ and $R_{y}$ can be given by

$$
R_{x}=D\left(1-\gamma_{i}\right) / 2, R_{y}=D f_{i} /\left(2 f_{i}-1\right)
$$

Where $\gamma_{i}=D \cos \theta_{i k} / D_{m}$.

When the outer raceway contacts with the rolling element, $R_{x}$ and $R_{y}$ can be calculated as

$$
R_{x}=D f_{o} /\left(2 f_{o}-1\right), R_{y}=D\left(1+\gamma_{o}\right) / 2
$$

Where $\gamma_{o}=D \cos \theta_{o k} / D_{m}$.

It is assumed that the initial variables and the corresponding errors of Eqs.18 and 19 are $\delta_{k}^{0}=\left\{U_{k}, V_{k}, \delta_{i k}, \delta_{o k}\right\}$ and $\varepsilon_{k}^{0}=\left\{\varepsilon_{1}, \varepsilon_{2}, \varepsilon_{3}, \varepsilon_{4}\right\}$, respectively. The position geometry and the force balance equations can be rewritten as

$$
\begin{gathered}
\left(U_{i k}-U_{k}\right)^{2}+\left(V_{i k}-V_{k}\right)^{2}-\Delta_{i k}^{2}=\varepsilon_{1} \\
U_{k}^{2}+V_{k}^{2}-\Delta_{o k}^{2}=\varepsilon_{2} \\
Q_{o k} \cos \theta_{o k}-M_{g k} \sin \theta_{o k} / D-Q_{i k} \cos \theta_{i k}+M_{g k} \sin \theta_{i k} / D-F_{c k}=\varepsilon_{3} \\
Q_{o k} \sin \theta_{o k}+M_{g k} \cos \theta_{o k} / D-Q_{i k} \sin \theta_{i k}-M_{g k} \cos \theta_{i k} / D=\varepsilon_{4}
\end{gathered}
$$

To obtain four parameters $U_{k}, V_{k}, \delta_{i k}$ and $\delta_{o k}$, Newton-Raphson method is used for iteration. 


$$
\left\{\delta_{k}^{n+1}\right\}=\left\{\delta_{k}^{n}\right\}-\left[a_{i j}\right]^{-1}\left\{\varepsilon_{k}^{n}\right\} \quad(n=0,1,2 \ldots ; i, j=1,2,3,4)
$$

Where $\left[a_{i j}\right]$ represents the matrix element, $\partial \varepsilon_{i} / \partial \delta_{j}$.

Based on the contact force between the rolling element and inner raceway, the external load acting on the inner raceway can be given by

$$
\begin{gathered}
F_{x_{i}}=\sum_{k=1}^{N}\left(Q_{i k} \sin \theta_{i k}+M_{g k} \cos \theta_{i k} / D\right) \\
F_{y_{i}}=\sum_{k=1}^{N}\left(Q_{i k} \cos \theta_{i k}-M_{g k} \sin \theta_{i k} / D\right) \cos \varphi_{k} \\
F_{z_{i}}=\sum_{k=1}^{N}\left(Q_{i k} \cos \theta_{i k}-M_{g k} \sin \theta_{i k} / D\right) \sin \varphi_{k} \\
M_{y i}=\sum_{k=1}^{N}\left\{r_{i c}\left(Q_{i k} \sin \theta_{i k}+M_{g k} \cos \theta_{i k} / D\right)-f_{i} M_{g k}\right\} \sin \varphi_{k} \\
M_{z i}=\sum_{k=1}^{N}\left\{r_{i c}\left(Q_{i k} \sin \theta_{i k}+M_{g k} \cos \theta_{i k} / D\right)-f_{i} M_{g k}\right\} \cos \varphi_{k}
\end{gathered}
$$

By derivative of the external force vector $\mathbf{F}=\left(F_{x}, F_{y}, F_{z}, M_{y}, M_{z}\right)$ with respect to the displacement vector $\mathbf{d}=\left(\Delta \delta_{x}, \Delta \delta_{y}, \Delta \delta_{z}, \Delta \gamma_{y}, \Delta \gamma_{z}\right)$, the equivalent stiffness matrix of the ACBB can be obtained as

$$
\mathbf{K}_{I}=\partial \mathbf{F} / \partial \mathbf{d}
$$

Combining the rigid disc, Timoshenko elastic beam and ACBB models, the nonlinear dynamic equations of the crankshaft-bearing system can be expressed as

$$
[M] \ddot{\mathbf{x}}+[C] \dot{\mathbf{x}}+\mathbf{K x}+\mathbf{R}(\mathbf{x})=\mathbf{F}(\mathbf{t})
$$

Where $[\mathbf{M}]$ represents the mass matrix of the ACBB, $[\mathbf{M}]=\left[\mathbf{M}^{b}\right]+\left[\mathbf{M}^{d}\right],[\mathbf{C}]$ denotes the damping matrix, $[\mathbf{C}]=\left[\mathbf{G}^{b}\right]+\left[\mathbf{G}^{d}\right]+\left[\mathbf{C}^{s}\right],[\mathbf{K}]$ is the stiffness matrix, $[\mathbf{K}]=\left[\mathbf{K}^{\mathbf{b}}\right]+\left[\mathbf{K}^{\mathbf{b}}\right]_{p}+\left[\mathbf{K}_{B}\right]-\omega^{2}\left[\mathbf{M}^{b}\right]_{c}$

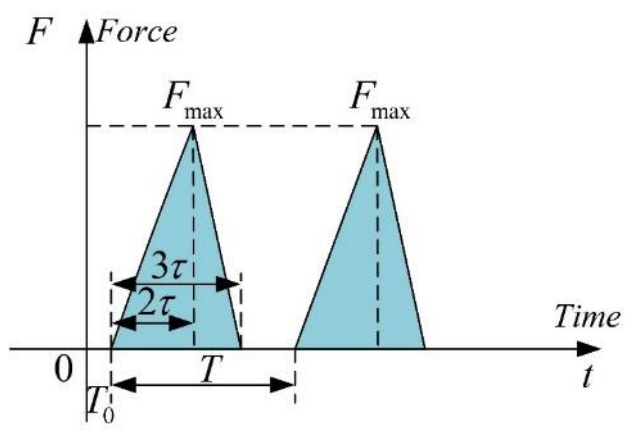

Fig.10 Blanking force

When the MHSPP operates under blanking condition, the impact force between the upper and lower dies can be simplified as a triangular wave pulse load [23], as shown in Fig. 10. Its mathematical expression can be written as 


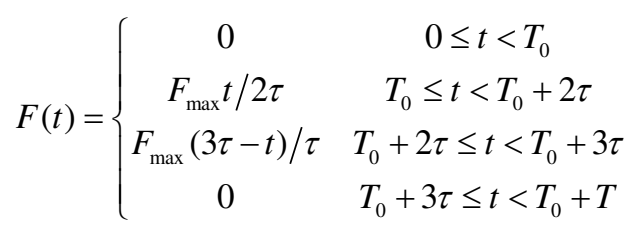

Where $T_{0}$ is the period of the pulse function, $\tau$ is a variable related to the pulse width, $F_{\max }$ is the amplitude of the blanking force.

Table 1 Dynamic simulation parameters of the crankshaft-bearing system

\begin{tabular}{|c|c|c|c|c|c|}
\hline Number of element & Length $(\mathrm{m})$ & Diameter $(\mathrm{m})$ & Number of element & Length (m) & Diameter $(\mathrm{m})$ \\
\hline 1 & 0.0230 & 0.0350 & 13 & 0.0275 & 0.0575 \\
\hline 2 & 0.0060 & 0.0450 & 14 & 0.0115 & 0.1000 \\
\hline 3 & 0.0190 & 0.0850 & 15 & 0.0475 & 0.0575 \\
\hline 4 & 0.0500 & 0.0650 & 16 & 0.0115 & 0.1000 \\
\hline 5 & 0.0254 & 0.1926 & 17 & 0.0275 & 0.0575 \\
\hline 6 & 0.0956 & 0.0650 & 18 & 0.01725 & 0.1000 \\
\hline 7 & 0.0220 & 0.0675 & 19 & 0.0630 & 0.0750 \\
\hline 8 & 0.0220 & 0.1100 & 20 & 0.0220 & 0.1100 \\
\hline 9 & 0.0040 & 0.1100 & 21 & 0.0040 & 0.1100 \\
\hline 10 & 0.0220 & 0.1100 & 22 & 0.0220 & 0.1100 \\
\hline 11 & 0.0630 & 0.0750 & 23 & 0.0165 & 0.0400 \\
\hline 12 & 0.01725 & 0.1000 & & & \\
\hline Disk (node) & Mass (kg) & \multicolumn{2}{|c|}{ Polar moment of inertia $J_{p} /\left(\mathrm{kg} \cdot \mathrm{m}^{2}\right)$} & \multicolumn{2}{|c|}{ Diameter inertia moment $J_{d} /\left(\mathrm{kg} \cdot \mathrm{m}^{2}\right)$} \\
\hline 5 & 200 & & 26 & & \\
\hline \multicolumn{2}{|c|}{ Parameters } & Value & \multicolumn{2}{|c|}{ Parameters } & Value \\
\hline \multicolumn{2}{|c|}{ Number of bearing balls $N$} & 10 & \multicolumn{2}{|c|}{ Pitch diameter of bearing $D_{m} /(\mathrm{mm})$} & 85 \\
\hline \multicolumn{2}{|c|}{ Mass of bearing ball $m /(\mathrm{kg})$} & $3.6273 \times 10^{-2}$ & \multicolumn{2}{|c|}{ Transverse shear form factor $k_{s}$} & 0.9 \\
\hline \multicolumn{2}{|c|}{ Diameter of the bearing ball $D /(\mathrm{mm})$} & 11.9062 & \multicolumn{2}{|c|}{ Density of crank shaft $\rho_{c} /\left(\mathrm{kg} / \mathrm{m}^{3}\right)$} & $7.87 \times 10^{3}$ \\
\hline \multicolumn{2}{|c|}{ Young's modulus of crank shaft $E_{c} /\left(\mathrm{N} / \mathrm{m}^{2}\right)$} & $2.15 \times 10^{11}$ & \multicolumn{2}{|c|}{ Poisson's ratio of bearing ball $v_{1}$} & 0.29 \\
\hline \multicolumn{2}{|c|}{ Young's modulus of inner/outer ring $E_{2} /\left(\mathrm{N} / \mathrm{m}^{2}\right)$} & $2.37 \times 10^{11}$ & \multicolumn{2}{|c|}{ Poisson's ratio of inner or outer ring $v_{2}$} & 0.32 \\
\hline \multicolumn{2}{|c|}{ Young's modulus of bearing ball $E_{1} /\left(\mathrm{N} / \mathrm{m}^{2}\right)$} & $2.14 \times 10^{11}$ & \multicolumn{2}{|c|}{ Shear modulus of crank shaft $G_{c} /\left(\mathrm{N} / \mathrm{m}^{2}\right)$} & $0.8 \times 10^{11}$ \\
\hline
\end{tabular}

The dynamic simulation parameters of the crankshaft-bearing system are listed in Table 1 .

When the crankshaft speed and punching force are $200 \mathrm{rpm}$ and $10 \mathrm{kN}$, respectively, vertical vibration displacement and trajectories of the crankshaft sections 1 (A), 4 (B), 7 (C), 11 (D), 15 (E), $17(\mathrm{~F})$ and $19(\mathrm{G})$ under both no-load and blanking conditions neglecting the thermal effect are shown in Figs. 11 and 12.

It can be observed from Fig. 11 that the maximum vertical vibration displacement under noload condition occurs on the shaft section 17 and its corresponding amplitude is $1.3 \times 10^{-5} \mathrm{~m}$, while the minimum vertical vibration displacement exists on the shaft sections 1 and 4 that are far away from the eccentric shaft section. Vertical vibration displacement under blanking condition increases due to the punching force. The maximum vertical vibration displacement under blanking condition occurs on the shaft sections 15 and 17 and the corresponding amplitude is $3.8 \times 10^{-5} \mathrm{~m}$. Figure 12 shows that trajectories of crankshaft centres are no longer overlap and vertical vibration 
displacement under blanking condition is larger than that under no-load condition. Therefore, the smallest radial stiffness of the crankshaft-bearing system is located on the shaft section 17.

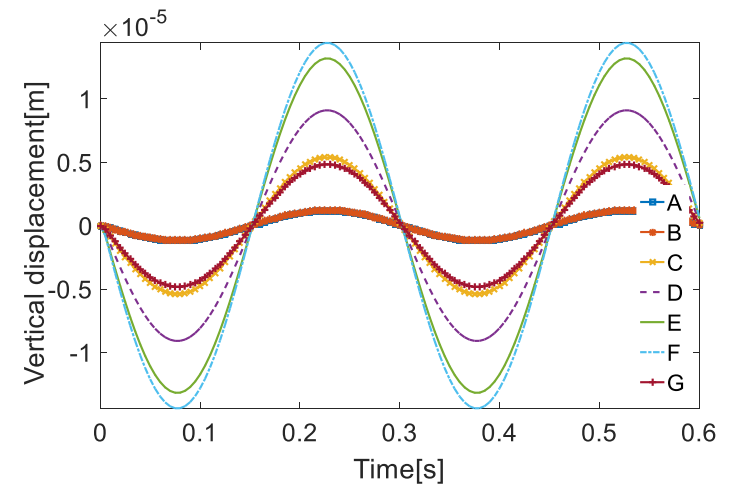

(a)

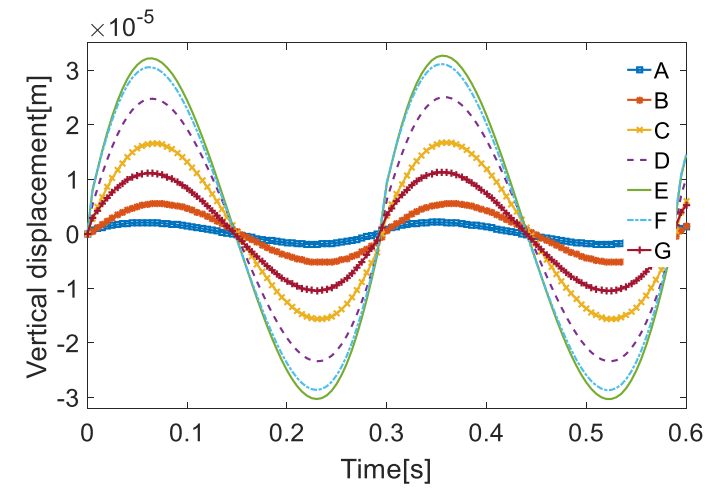

(b)

Fig.11 Vertical displacement of the crankshaft sections neglecting the thermal effect: (a) no-load, (b) blanking

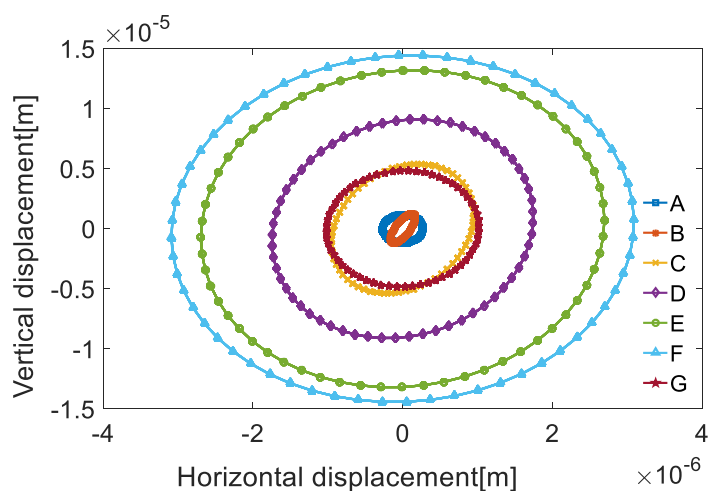

(a)

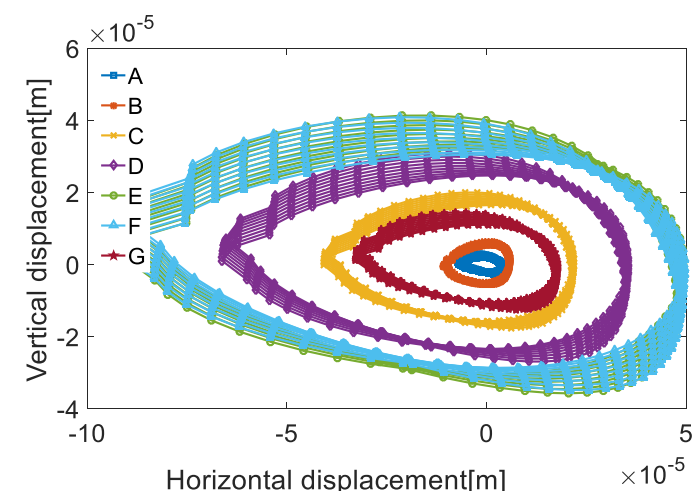

(b)

Fig.12 Trajectories of the crankshaft sections neglecting the thermal effect: (a) no-load, (b) blanking

\section{Improved model of multilink mechanism with the crankshaft-bearing structure}

When the press is working, heat generation produces between rolling elements and inner/outer raceways as a result of friction. Due to the influence of heat conduction and convection, the temperature rise of the bearings and adjacent components increases significantly and thermal deformation brings forth. The axial and radial displacements caused by the thermal expansion of ACBB affect the stiffness of the bearings and vibration response characteristics of the crankshaft-bearing system. In order to predict the position error of BDP for MHSPP accurately, it's essential to develop a dynamic model of planar flexible multilink mechanism with clearance considering the thermal-mechanical coupling effect of the crankshaft-bearing structure.

\subsection{TNM of the crankshaft-bearing system}

To simplify the complexity of the model, only variable bearing stiffness as a result of thermal expansion is considered in this work, while the effect of thermal deformation of crankshaft on the dynamic characteristics of crankshaft-bearing system is neglected. According to the physical 
structure of the crankshaft-bearing system, it is discretized into 70 nodes and the corresponding TNM is developed, as shown in Fig. 13.

The temperature on the centroid of each node is regarded as the average temperature of the node. Heat transfer of each node is carried out by means of heat conduction and thermal contact resistance between two adjacent contact nodes exists. Nodes that are contact with environment directly transfer heat with air through convection and there exits convection heat transfer resistance. The energy transfer relationship among nodes in the TNM is shown in Fig. 14. Based on the principle of energy conservation, the finite difference (FD) equation is used to describe the temperature field of nodes.

$$
\sum_{n=1}^{4}\left(T_{n}-T_{i}\right) / R_{i, n}+q_{i}=C_{i} m_{i} \partial T_{i} / \partial t
$$

Where $T_{i}$ is the temperature of node $i, T_{n}$ is the temperature of node $n$, which is adjacent to node $i, R_{i, n}$ is the thermal contact resistance between nodes $i$ and $n, q_{i}$ is the friction heat at the contact zone of rolling element, $C_{i}$ is the thermal capacity of node $i, m_{i}$ is the mass of node $i$.

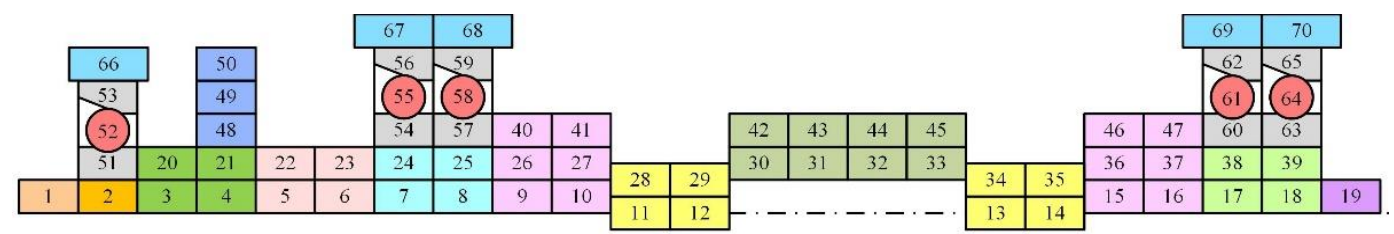

Fig.13 TNM of the crankshaft-bearing coupling system

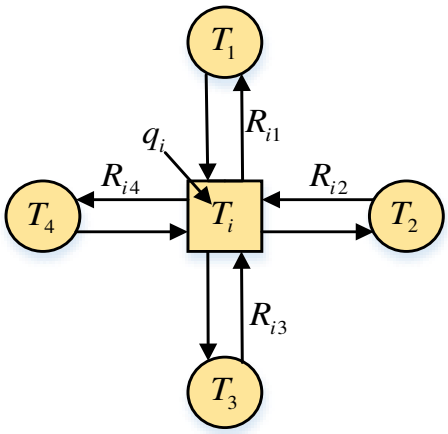

Fig.14 Energy transfer relationship of thermal network nodes

\section{(1) Heat generation of bearing}

The heat of the crankshaft-bearing system mainly results from the friction between rolling elements and inner raceway, rolling elements and outer raceway. The total heat generated from the bearing due to friction torque can be calculated as

$$
q=1.047 \times 10^{-4} \omega M
$$

Where $M$ is the total friction torque of the bearing, $M=M_{1}+M_{2}, M_{1}$ is the friction torque of the bearing, $M_{2}$ is the viscous friction torque due to the lubricant.

Friction torque $M_{1}$ of the bearing can be given by

$$
M_{1}=f_{1} F_{1} d_{m}
$$


Where $f_{1}$ represents the factor with respect to the types of bearing and external load, $f_{1}=N\left(F_{s} / C_{s}\right)^{y}, F_{s}=0.5 F_{r}+0.38 F_{a}, F_{s}$ is the equivalent static load of bearing, $C_{s}$ is the rated static load, $F_{1}=\max \left(0.9\left(F_{a} \cot \theta-0.1 F_{r}\right), F_{r}\right), d_{m}=(1+\alpha \Delta T)\left(D_{i o}+D_{o i}\right) / 2, F_{r}$ is the radial load, $F_{a}$ is the axial preload, $\theta$ is the contact angle of the ACBB, $\alpha$ is the thermal expansion coefficient of the bearing, $\Delta T$ is the temperature rise of the rolling element, $D_{i o}$ is the outer diameter of the inner raceway, $D_{o i}$ is the inner diameter of the outer raceway.

The viscous friction torque $M_{2}$ as a result of the lubricant can be expressed as

$$
M_{2}=\left\{\begin{array}{cc}
10^{-7} \cdot\left(v_{0} n\right) f_{v} d_{m}^{3} & v_{0} n \geq 2000 \\
10^{-7} \cdot 160 f_{v} d_{m}^{3} & v_{0} n<2000
\end{array}\right.
$$

Where $v_{0}$ represents the kinematic viscosity of the lubricant under the working temperature of the $\mathrm{ACBB}, f_{v}$ is the factor dependent on the types of the bearing and lubrication. For the thin oil lubrication, $f_{v}=4$.

\section{(2) Thermal contact resistance}

Thermal contact resistance between the rolling elements and outer/inner raceways for the $\mathrm{ACBB}$ can be written as

$$
\begin{gathered}
R_{b}=\Psi(a / b) /\left(4 k_{b} a\right) \\
\Psi(a / b)=2 F(e, \pi / 2) / \pi
\end{gathered}
$$

Where $k_{b}$ represents the thermal conductivity between the balls and outer/inner raceways, $a=a^{*}\left\{(3 / 4)[Q /(A+B)]\left[\left(1+v_{1}^{2}\right) / E_{1}+\left(1+v_{2}^{2}\right) / E_{2}\right]\right\}^{1 / 3}, a$ and $b$ are the semi-axis of the ellipse contact area, $v_{1}$ and $v_{2}$ are the Poisson's ratio of two contact bodies, $E_{1}$ and $E_{2}$ are the elastic modulus of two contact bodies, $A=(1 / 2)\left(1 / r_{1}^{I}+1 / r_{1}^{R}\right), B=(1 / 2)\left(1 / r_{2}^{O}+1 / r_{2}^{R}\right), r_{1}^{I}$ and $r_{1}^{R}$ are the contact curvature radius of the inner raceway and rolling element, $a^{*}=[(I+J) / \pi]^{1 / 3}$, $I=2[F(e, \pi / 2)-E(e, \pi / 2)] / e^{2}, J=2\left[F(e, \pi / 2)\left(1-e^{2}\right)-E(e, \pi / 2)\right], I / J=A / B, r_{2}^{O}$ and $r_{2}^{R}$ are the contact curvature radius of the outer raceway and rolling element, $F(e, \pi / 2)$ and $E(e, \pi / 2)$ are the complete elliptic integral of the first and second kind, respectively, which can be defined as

$$
\begin{gathered}
F(e, \pi / 2)=\frac{1}{2}\left\{1+\left(\frac{1}{2}\right)^{2} e^{2}+\left[\frac{1 \cdot 3}{2 \cdot 4}\right]^{2} e^{4}+\cdots+\left[\frac{\left(2 b^{*}-1\right)\left(2 b^{*}-3\right) \cdots 3 \cdot 1}{2 b^{*}\left(2 b^{*}-2\right) \cdots 4 \cdot 2}\right]^{2} e^{2 b^{*}}\right\} \\
E(e, \pi / 2)=\frac{\pi}{2}\left\{1-\left(\frac{1}{2}\right)^{2} e^{2}-\left(\frac{1 \cdot 3}{2 \cdot 4}\right)^{2} \frac{e^{4}}{3}-\cdots-\left[\frac{\left(2 b^{*}-1\right)\left(2 b^{*}-3\right) \cdots 3 \cdot 1}{2 b^{*}\left(2 b^{*}-2\right) \cdots 4 \cdot 2}\right]^{2} \frac{e^{2 b^{*}}}{2 b^{*}-1}\right\}
\end{gathered}
$$

Thermal contact resistance between inner raceway and crank shaft can be given by

$$
R_{c}=1 / h_{c}
$$


Where $h_{c}$ is the thermal contact conductance between inner raceway and crank shaft, which can be determined as [46]

$$
h_{c}=\left\{\begin{array}{cc}
1.13\left(\frac{k_{c} \tan \varphi}{\sigma}\right)\left(\frac{p}{H}\right)^{0.94} & \psi \geq 1 \\
1.55\left(\frac{k_{c} \tan \varphi}{\sigma}\right)\left(\frac{p \sqrt{2}}{H \tan \varphi}\right)^{0.94} & \psi<1
\end{array}\right.
$$

Where $k_{c}$ represents the equivalent thermal conductivity between two contact surfaces, $k_{c}=2 k_{1} k_{2} /\left(k_{1}+k_{2}\right), k_{1}$ and $k_{2}$ are the thermal conductivity of the inner raceway and crank shaft, respectively, $E=2\left[\left(1-v_{1}^{2}\right) / E_{I}+\left(1-v_{2}^{2}\right) / E_{C}\right]^{-1}, E$ is the equivalent elastic modulus, $E_{I}$ and $E_{C}$ are the elastic modulus of the inner raceway and crank shaft, respectively, $p$ is the contact pressure, $\sigma$ is the Gaussian surface roughness, $\sigma=1.25 \sqrt{\left(\sigma_{1}^{2}+\sigma_{2}^{2}\right)}, \psi$ is the plasticity index, $\psi=E \tan \varphi / H, H$ is the hardness of the softer material between two contact bodies, $\tan \varphi=\sqrt{(\text { slope })_{1}^{2}+(\text { slope })_{2}^{2}},(\text { slope })_{1}$ and $(\text { slope })_{2}$ are the slopes of inner raceway and crack shaft.

Thermal convection occurs between the crankshaft-bearing system and surrounding air, including forced convection between rotation bodies and air, and free convection between stationary surfaces and air. The convective heat transfer coefficient can be calculated as

$$
h=N u \cdot \lambda / d
$$

Where $N u$ represents the Nusselt number, $\lambda$ is the thermal conductivity of air, $d$ is the diameter of the crank shaft rotor.

The Nusselt number of the combined flow on the surface of the crankshaft can be given by

$$
N u=0.6366(\operatorname{Re} \cdot \operatorname{Pr})^{1 / 2}
$$

Where $\operatorname{Re}=\omega d^{2} /\left(2 v_{\text {air }}\right), \operatorname{Pr}=v_{\text {air }} / \alpha_{\text {air }}, v_{\text {air }}$ and $\alpha_{\text {air }}$ are the kinematic viscosity and thermal diffusion of the surrounding air, respectively.

The Nusselt number of the highly turbulent air flow inside the crankshaft-bearing system can be expressed as

$$
N u=0.409\left(T_{a}^{2} / F_{g}\right)^{0.241}
$$

Where $T_{a}=\omega \sqrt{r_{m}} d^{1.5} / v_{\text {air }}, F_{g}=\left(\pi^{4} / 1697\right)\left[1-d /\left(2 r_{m}\right)\right]^{-2} / P, r_{m}$ is the average radius of the crankshaft, $P=0.0571\left[1-0.652\left(d /\left(r_{m}\left(1-d /\left(2 r_{m}\right)\right)\right)\right)\right]+0.00056 \sqrt{1-0.652\left(d /\left(r_{m}\left(1-d /\left(2 r_{m}\right)\right)\right)\right)}$.

The Nusselt number of free convection between the bearing support and air can be given by

$$
N u=\left\{0.6+0.387 R_{a_{D}}^{1 / 6} /\left[1+(0.559 / \operatorname{Pr})^{9 / 16}\right]^{8 / 27}\right\}^{2}
$$

Where $R_{a_{D}}=2\left(T_{s}-T_{\text {air }}\right) D^{3} g /\left[\left(T_{s}+T_{\text {air }}\right) \alpha_{\text {air }} v_{\text {air }}\right], T_{s}$ is the temperature of the crankshaft rotor, $T_{\text {air }}$ is the temperature of surrounding air, $g=9.8 \mathrm{~m} / \mathrm{s}^{2}$. 


\section{(3) Model verification and temperature field analysis}

The parameters of TNM for the crankshaft-bearing system are listed in Table 2. When the rotation speed of MHSPP is $200 \mathrm{rpm}$ with the initial temperature of the surrounding air $25^{0} \mathrm{C}$, the simulated and experimental temperature rise of four bearings for the crankshaft-bearing system under no-load condition is shown in Fig. 15.

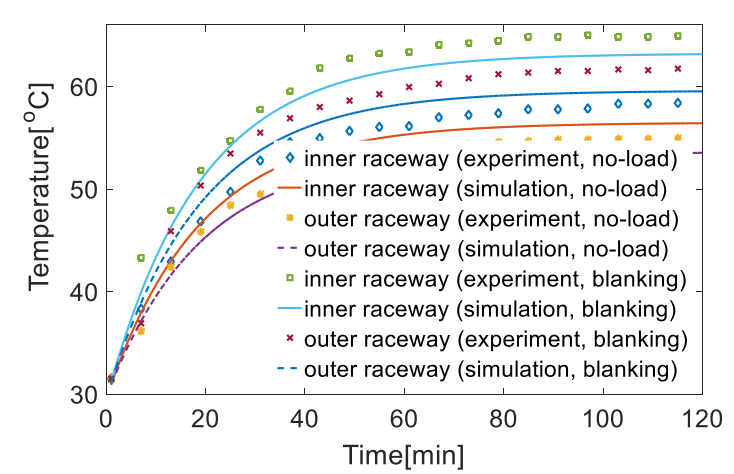

(a)

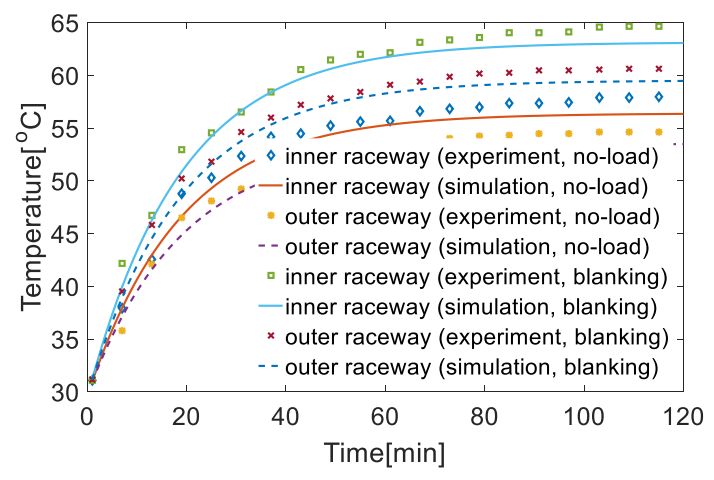

(c)

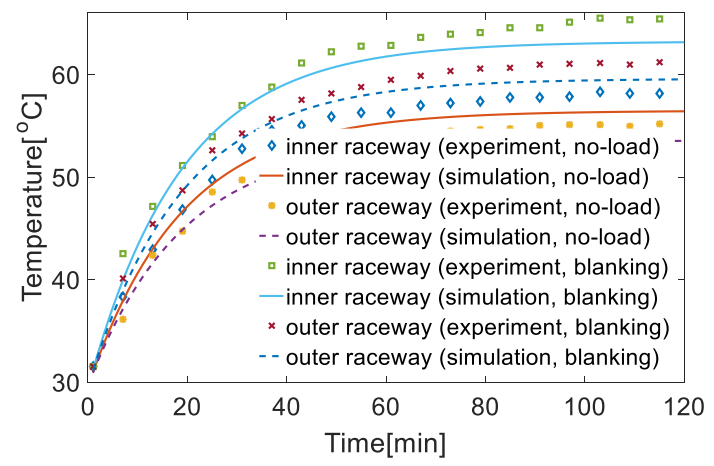

(b)

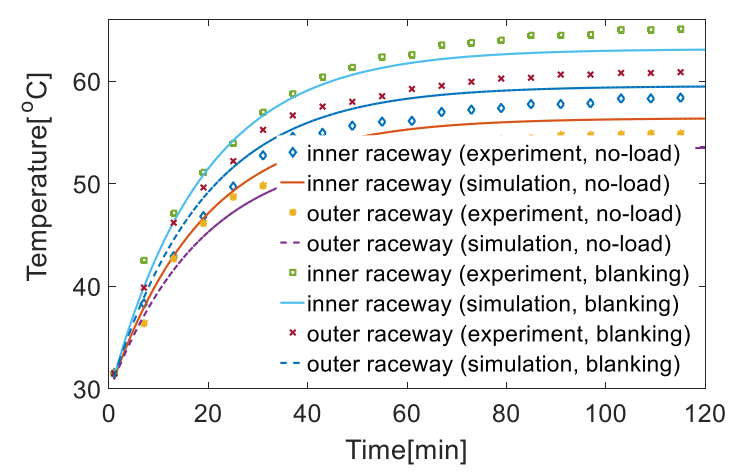

(d)

Fig.15 Temperature rise of four bearings under no-load condition: (a) No.2, (b) No.3, (c) No.4, (d) No.5

Table 2 Parameters of TNM for the crankshaft-bearing system

\begin{tabular}{|c|c|c|c|}
\hline Parameters & Value & Parameters & Value \\
\hline $\begin{array}{l}\text { Kinematic viscosity of } \\
\text { the lubricant } v_{0} /\left(\mathrm{mm}^{2} / \mathrm{s}\right)\end{array}$ & 5 & $\begin{array}{l}\text { Thermal expansion coefficient of the } \\
\text { bearing } \alpha /(1 / \mathrm{K})\end{array}$ & $1.25 \times 10^{-5}$ \\
\hline $\begin{array}{l}\text { Rated static load of } \\
\qquad \mathrm{ACBB} C_{s} /(\mathrm{kN})\end{array}$ & 45.7 & $\begin{array}{l}\text { Thermal expansion coefficient of the inner ring } \\
\qquad \text { raceway } \alpha_{b i} /(1 / \mathrm{K})\end{array}$ & $1.25 \times 10^{-5}$ \\
\hline $\begin{array}{l}\text { Diameter of inner ring } \\
\text { raceway } D_{i o} /(\mathrm{m})\end{array}$ & 0.11 & $\begin{array}{l}\text { Thermal expansion coefficient of the outer ring } \\
\text { raceway } \alpha_{b e} /(1 / \mathrm{K})\end{array}$ & $1.25 \times 10^{-5}$ \\
\hline $\begin{array}{l}\text { Diameter of outer ring } \\
\text { raceway } D_{o i} /(\mathrm{m})\end{array}$ & 0.06 & $\begin{array}{l}\text { Thermal expansion coefficient of the bearing } \\
\text { housing } \alpha_{h} /(1 / \mathrm{K})\end{array}$ & $1.15 \times 10^{-5}$ \\
\hline $\begin{array}{l}\text { Thermal conductivity of } \\
\text { air } \lambda /(\mathrm{W} /(\mathrm{m} \cdot \mathrm{K}))\end{array}$ & 0.023 & $\begin{array}{l}\text { Thermal expansion coefficient of the rolling } \\
\text { element } \alpha_{1} /(1 / \mathrm{K})\end{array}$ & $1.25 \times 10^{-5}$ \\
\hline
\end{tabular}


of four bearings tend to be stable at about 90 min under no-load condition, and the stable temperature of the inner raceway is larger than that of the outer raceway.

The steady-state temperature distribution and temperature rise variation of the network nodes for the crankshaft-bearing system are shown in Figs. 16 and 17.

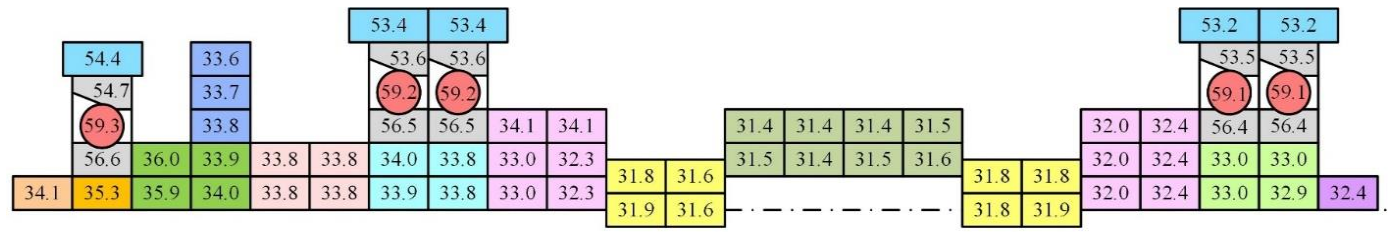

(a)

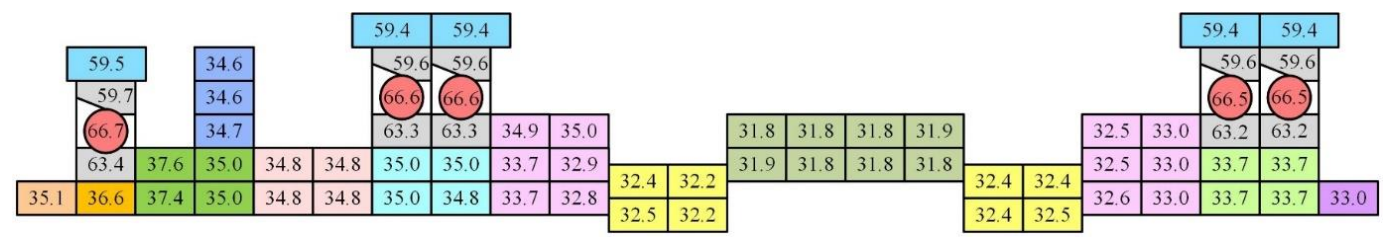

(b)

Fig.16 Steady-state temperature distribution of the crankshaft-bearing system: (a) no-load, (b) blanking

Figures 16 and 17 show that the main heat of MHSPP is generated due to the friction between the rolling elements and inner/outer raceways. The maximum temperature rise of the crankshaftbearing system is concentrated on the nodes near the rolling elements of bearing and the corresponding average temperature rise reaches $25{ }^{\circ} \mathrm{C}$, while the average temperature rise of the remaining nodes is only $5{ }^{\circ} \mathrm{C}$. Therefore, variable stiffness of bearing due to temperature rise will affect the position accuracy of the slider's BDP for MHSPP.

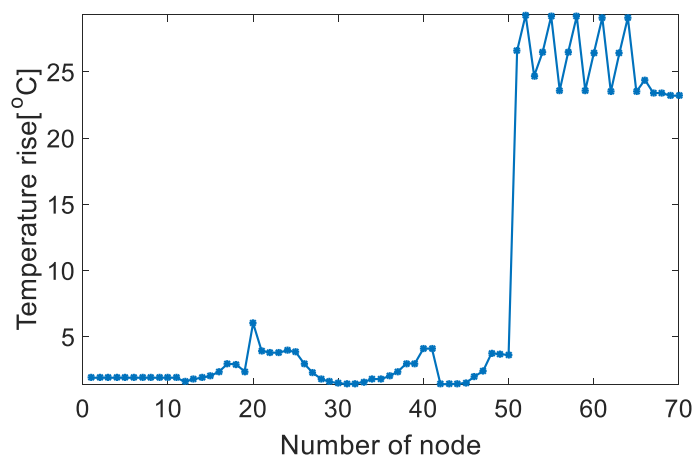

(a)

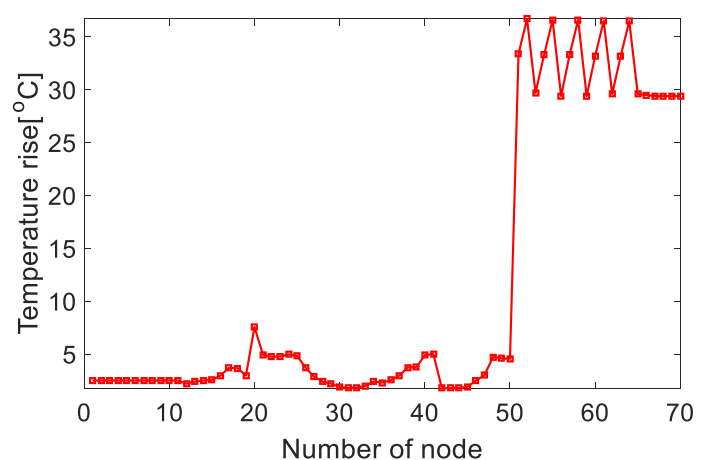

(b)

Fig.17 Temperature rise variation of network nodes for the crankshaft-bearing system: (a) no load, (b) blanking

\subsection{Thermal-mechanical coupling model of the crankshaft-bearing system}

Positioning mode is adopted to perform the preload of the bearing in the crankshaft-bearing structure of MHSPP, as shown in Fig. 18. The relative axial displacement between inner and outer raceways under static condition is caused by preload acting on the bearings, which can be divided into two stages. In the first stage, the axial clearance $0.5 P_{e}$ is eliminated and a free contact angle $\alpha_{0}$ is produced. Then, a new axial displacement $\delta_{p}$ causes the internal contact deformation 
during the second stage. For the positioning preload mode, the axial displacement between the inner and outer raceways is limited and the total displacement $\delta$ during two stages remains constant, $\delta=0.5 P_{e}+\delta_{p}$.

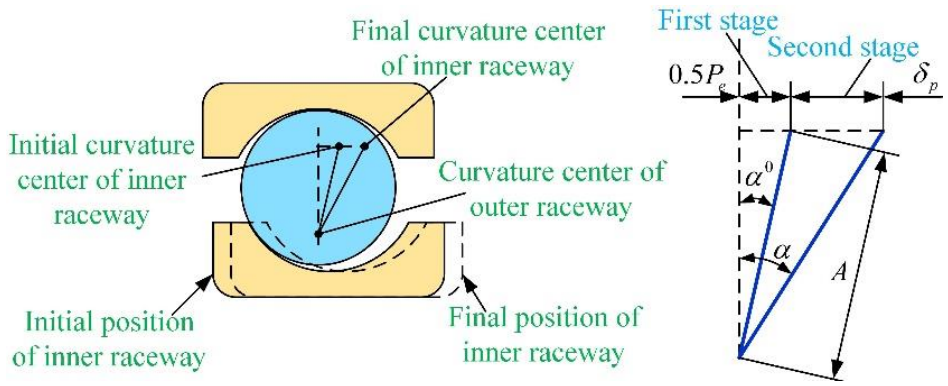

Fig.18 Preload of the ACBB under positioning mode

The radial clearance can be expressed as

$$
P_{d}=d_{o}-d_{i}-2 D
$$

Where $d_{i}$ and $d_{o}$ are the contact diameters of the inner and outer raceways, respectively.

The free contact angle $\alpha_{0}$ of the ACBB can be calculated as

$$
\alpha^{0}=\arccos \left[\left(B D-0.5 P_{d}\right) /(B D)\right]
$$

Based on the Jones model of the bearing, the axial force $F_{p}$ can be given by

$$
F_{p}=Z D^{2} K \sin \alpha\left(\cos \alpha^{0} / \cos \alpha-1\right)^{3 / 2}
$$

Where $\alpha=\arctan \left[\left(\delta_{p}+B D \sin \alpha^{0}\right) /\left(B D \cos \alpha^{0}\right)\right]$

\section{(1) Radial thermal displacement of inner ring raceway}

The radial thermal displacement $u_{b i}$ of the inner ring raceway considering the effect of its temperature rise for the bearing can be calculated as

$$
u_{b i}=\alpha_{b i} \Delta T_{b i} d_{i}
$$

Where $\alpha_{b i}$ and $\Delta T_{b i}$ are the thermal expansion coefficient and temperature rise of the inner ring raceway, respectively.

The radial thermal displacement $u_{b i T}$ on the inner diameter of the bearing can be given by

$$
u_{b i T}=\alpha_{b i} \Delta T_{b i} d_{b i}
$$

Where $d_{b i}$ is the diameter of the inner ring raceway.

The radial thermal displacement $u_{s t}$ on the outer diameter of the crank shaft can be written as

$$
u_{s t}=\alpha_{s} \Delta T_{s}\left(1+\mu_{s}\right) d_{b i}
$$

Where $\alpha_{s}$ is the thermal expansion coefficient of the crank shaft, $\Delta T_{s}$ is the temperature rise of the corresponding shaft section, $\mu_{s}$ is the Poisson's ratio. 
The radial thermal displacement of the inner ring raceway due to the thermal expansion of the crank shaft can be written as

$$
u_{r i}=u_{b i}+\left(u_{s t}-u_{b i T}\right) d_{b i} / d_{i}
$$

\section{(2) Radial thermal displacement of outer ring raceway}

With the effect of temperature rise considered, the radial thermal displacement $u_{b e}$ of the outer ring raceway can be given by

$$
u_{b e}=\alpha_{b e} \Delta T_{b e} d_{o}
$$

Where $\alpha_{b e}$ is the thermal expansion coefficient of the outer ring raceway, $\Delta T_{b e}$ is the temperature rise of the outer ring raceway.

The radial thermal displacement $u_{b e T}$ on the outer diameter of the bearing can be calculated as

$$
u_{b e T}=\alpha_{b e} \Delta T_{b e} d_{b e}
$$

Where $d_{b e}$ is the diameter of the outer ring raceway.

The radial thermal displacement $u_{h}$ of the bearing housing can be expressed as

$$
u_{h}=\alpha_{h} \Delta T_{h}\left(1+\mu_{h}\right) d_{b e}
$$

Where $\alpha_{h}, \Delta T_{h}$ and $\mu_{h}$ represent the thermal expansion coefficient, temperature rise and Poisson's ratio of the bearing housing, respectively.

The radial thermal displacement of outer ring groove due to the thermal expansion of the bearing housing can be written as

$$
u_{r e}=u_{b e}+\left(u_{h}-u_{b e T}\right) d_{e} / d_{b e}
$$

The radial thermal displacement $u_{r}$ between the inner and outer ring grooves can be given by

$$
u_{r}=u_{r i}-u_{r e}
$$

\section{(3) Thermal displacement of rolling element}

The axial and radial displacements of the rolling element can be expressed as

$$
u_{b}=\alpha_{1} D \Delta T_{b}
$$

Where $\alpha_{1}$ and $\Delta T_{b}$ are the thermal expansion coefficient and temperature rise of the rolling element.

Temperature variation of bearings will lead to the geometric dimension changes of rolling elements and inner/outer raceways. It is assumed that the curvature centre position of outer raceway is fixed and the geometrical relationship of $\mathrm{ACBBs}$ considering the thermal-mechanical coupling effect is shown in Fig. 19. The distances between the final curvature centre of the inner ring groove and ball centre, between the final curvature centre of the outer ring groove and ball centre can be given by 


$$
\Delta_{i k}^{\prime}=r_{i}-D / 2+\delta_{i k}^{\prime}
$$

$$
\Delta_{o k}^{\prime}=r_{i}-D / 2+\delta_{o k}^{\prime}
$$

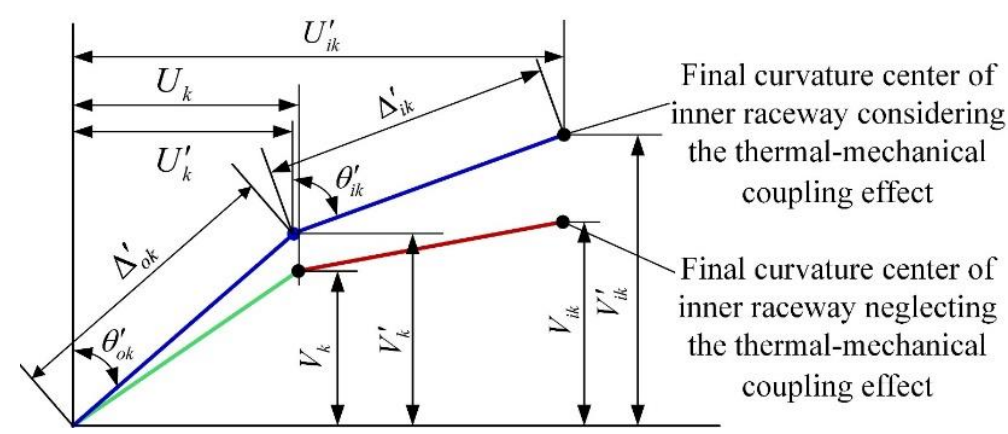

Fig.19 Geometric relationship of ACBBs considering the thermal-mechanical coupling effect

The geometric equations 27(a) and 27(b) can be updated as

$$
\begin{gathered}
\left(U_{i k}^{\prime}-U_{k}^{\prime}\right)^{2}+\left(V_{i k}^{\prime}-V_{k}^{\prime}\right)^{2}-\Delta_{i k}^{\prime 2}=0 \\
U_{k}^{\prime 2}+V_{k}^{\prime 2}-\Delta_{o k}^{\prime 2}=0
\end{gathered}
$$

Where $U_{i k}^{\prime}=B_{d} \sin \theta^{\prime}+\Delta \delta_{x}^{\prime}-\Delta \gamma_{z}^{\prime} r_{i c}^{\prime} \cos \varphi_{k}+\Delta \gamma_{y}^{\prime} r_{i c}^{\prime} \sin \varphi_{k}, V_{i k}^{\prime}=B_{d} \cos \theta^{\prime}+\Delta \delta_{y}^{\prime} \cos \varphi_{k}+\Delta \delta_{z}^{\prime} \sin \varphi_{k}+u_{r}$, $r_{i c}^{\prime}=D_{m} / 2+\left(f_{i}-0.5\right) D \cos \theta^{\prime}, \Delta \delta_{x}^{\prime}, \Delta \delta_{y}^{\prime}, \Delta \delta_{z}^{\prime}, \Delta \gamma_{y}^{\prime}$ and $\Delta \gamma_{z}^{\prime}$ represent the relative displacements between the inner and outer raceways of the ACBB under external loads considering the thermalmechanical coupling effect.

The force equilibrium equations of the rolling element can be given by

$$
\begin{gathered}
Q_{o k}^{\prime} \cos \theta_{o k}^{\prime}-\frac{M_{g k}^{\prime}}{D} \sin \theta_{o k}^{\prime}-Q_{i k}^{\prime} \cos \theta_{i k}^{\prime}+\frac{M_{g k}^{\prime}}{D} \sin \theta_{i k}^{\prime}-F_{c k}^{\prime}=0 \\
Q_{o k}^{\prime} \sin \theta_{o k}^{\prime}+\frac{M_{g k}^{\prime}}{D} \cos \theta_{o k}^{\prime}-Q_{i k}^{\prime} \sin \theta_{i k}^{\prime}-\frac{M_{g k}^{\prime}}{D} \cos \theta_{i k}^{\prime}=0
\end{gathered}
$$

Where $\theta_{i k}^{\prime}$ and $\theta_{o k}^{\prime}$ are the contact angles between the rolling element and inner/outer raceways considering the effect of thermal expansion, respectively. These can be calculated as

$$
\begin{gathered}
\theta_{o k}^{\prime}=\arctan \left[\left(U_{k}^{\prime}+u_{b}\right) /\left(V_{k}^{\prime}+u_{b}\right)\right] \\
\theta_{i k}^{\prime}=\arctan \left[\left(U_{i k}^{\prime}-U_{k}^{\prime}-u_{b}\right) /\left(V_{i k}^{\prime}-V_{k}^{\prime}+u_{r}-u_{b}\right)\right]
\end{gathered}
$$

Centrifugal force $F_{c k}^{\prime}$ and gyroscopic moment $M_{g k}^{\prime}$ can be written as

$$
\begin{gathered}
F_{c k}^{\prime}=m D_{m} \omega^{2}\left(\omega_{E} / \omega\right)_{k}^{\prime 2} \\
M_{g k}^{\prime}=J_{b} \omega^{2}\left(\omega_{B} / \omega\right)_{k}^{\prime}\left(\omega_{E} / \omega\right)_{k}^{\prime 2} \sin \alpha_{k}^{\prime}
\end{gathered}
$$

$\left(\omega_{B} / \omega\right)_{k}^{\prime}$ can be calculated as 


$$
\begin{gathered}
\left(\omega_{B} / \omega\right)_{k}^{\prime}=-1 /\left\{\left[\left(\cos \theta_{o k}^{\prime}+\tan \alpha_{k}^{\prime} \sin \theta_{o k}^{\prime}\right) /\left(1+\lambda \cos \theta_{o k}^{\prime}\right)\right.\right. \\
\left.+\left[\left(\cos \theta_{i k}^{\prime}+\tan \alpha_{k}^{\prime} \sin \alpha_{k}^{\prime} \sin \theta_{i k}^{\prime}\right) /\left(1-\lambda \cos \theta_{i k}^{\prime}\right)\right] \lambda \cos \alpha_{k}^{\prime}\right\} \\
\left(\omega_{E} / \omega\right)_{k}^{\prime}=\left[\cos \left(\theta_{i k}^{\prime}-\theta_{o k}^{\prime}\right)-\lambda \cos \theta_{o k}^{\prime}\right] /\left[1+\cos \left(\theta_{i k}^{\prime}-\theta_{o k}^{\prime}\right)\right] \\
\tan \alpha_{k}^{\prime}=\sin \theta_{i k}^{\prime} /\left(\cos \theta_{i k}^{\prime}-\lambda\right)
\end{gathered}
$$

Similarly, the equivalent stiffness matrix of the ACBB considering the effect of the thermal expansion can also be obtained through Eq. (30). When the crankshaft speed is $200 \mathrm{rpm}$, the preload and radial stiffness of the ACBB considering the effect of the thermal expansion are shown in Fig. 20.

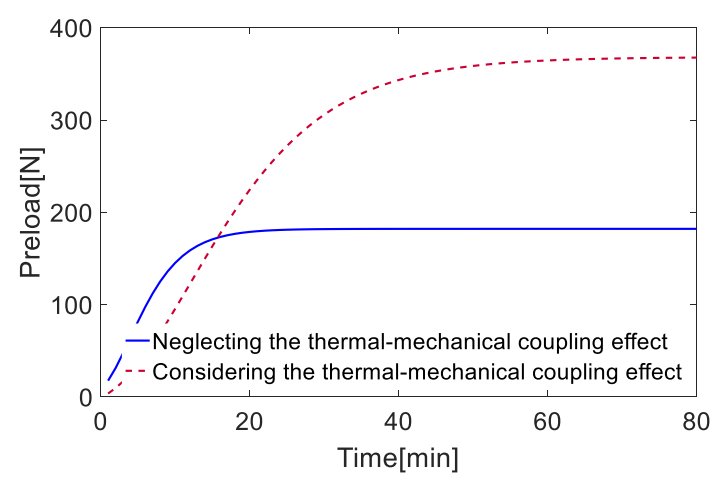

(a)

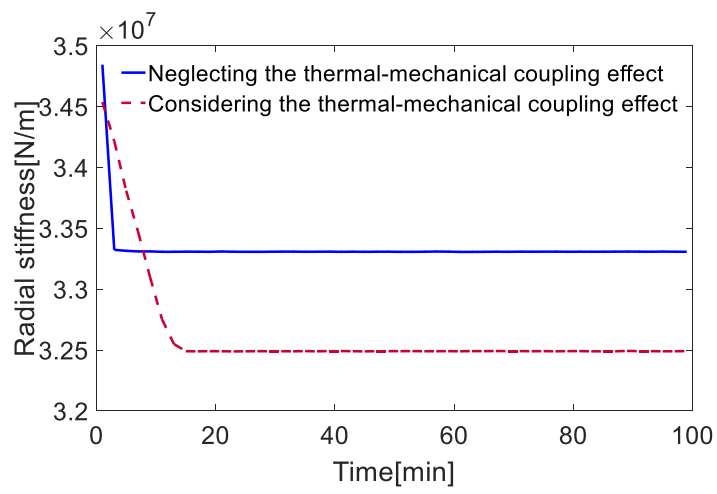

(b)

Fig.20 Preload and radial stiffness of ACBB considering the effect of thermal expansion: (a) preload, (b) radial stiffness

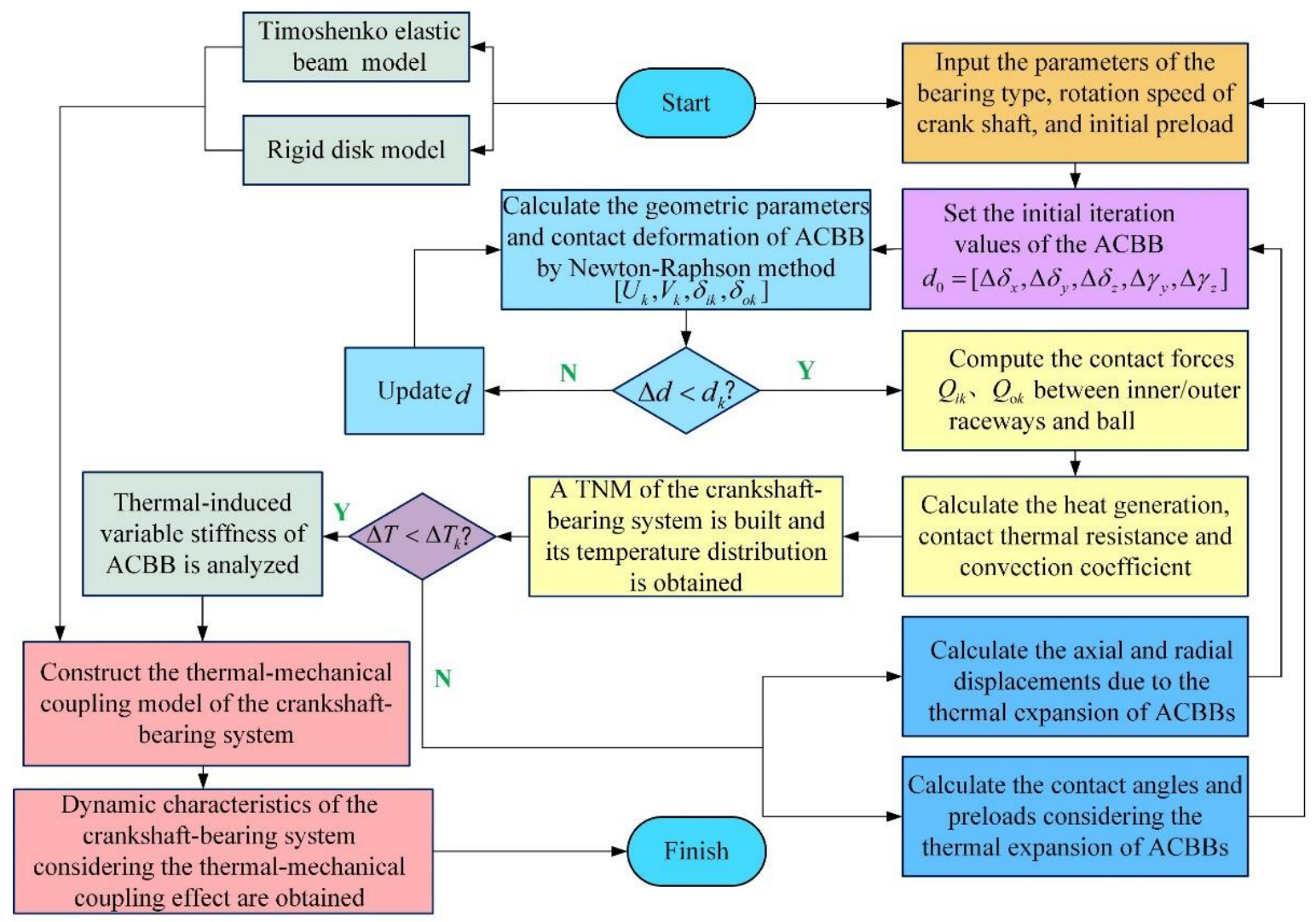

Fig.21 Dynamic simulation flow chart of crankshaft-bearing system considering the thermal-mechanical coupling effect Figure 20(a) shows that pretightening force of the ACBB tends to be stable after 50 min and 
the stable value reaches $380 \mathrm{~N}$ considering the thermal-mechanical coupling effect, while the stable preload becomes $190 \mathrm{~N}$ neglecting the thermal-mechanical coupling effect. The radial stiffness of $\mathrm{ACBB}$ reduces from $3.33 \times 10^{7}$ to $3.25 \times 10^{7} \mathrm{~N} / \mathrm{m}$ after 4 min due to the thermalmechanical coupling effect of bearing, as shown in Fig. 20(b). It's demonstrated that the preload rises significantly, while the radial stiffness decreases due to the bearing's thermal expansion.

The dynamic simulation flow chart of the crankshaft-bearing system considering the thermalmechanical coupling effect is shown in Fig. 21. When the crankshaft speed and punching force are $200 \mathrm{rpm}$ and $10 \mathrm{kN}$, the vertical vibration displacement and trajectories of the crank shaft sections under no-load and blanking conditions considering the thermal-mechanical coupling effect are shown in Figs. 22 and 23.

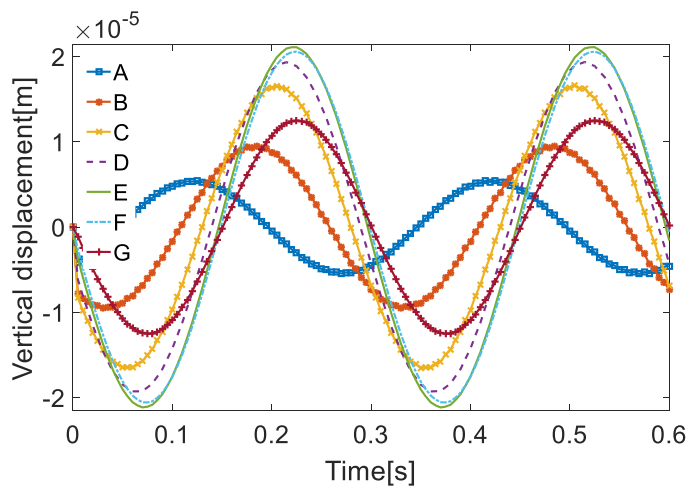

(a)

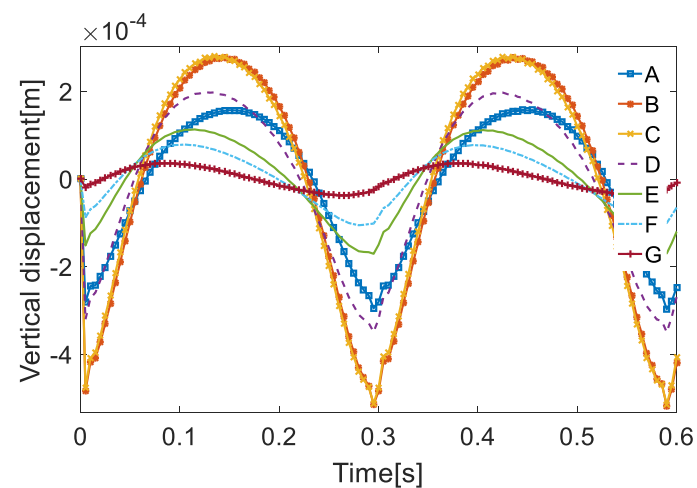

(b)

Fig.22 Vertical displacement of shaft sections considering the thermal-mechanical coupling effect: (a) no-load, (b) blanking

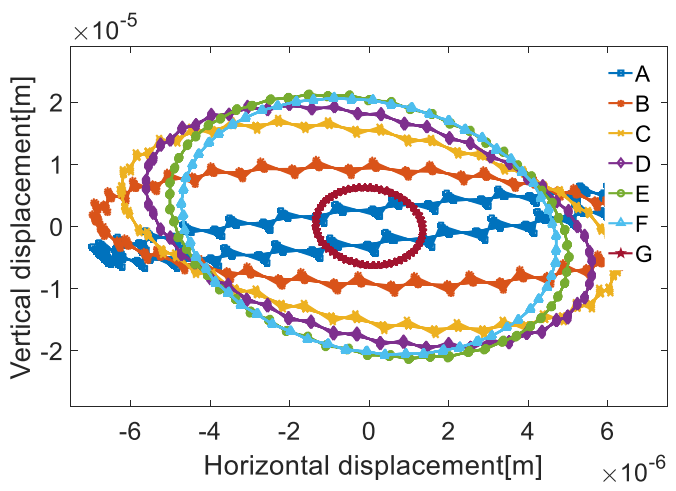

(a)

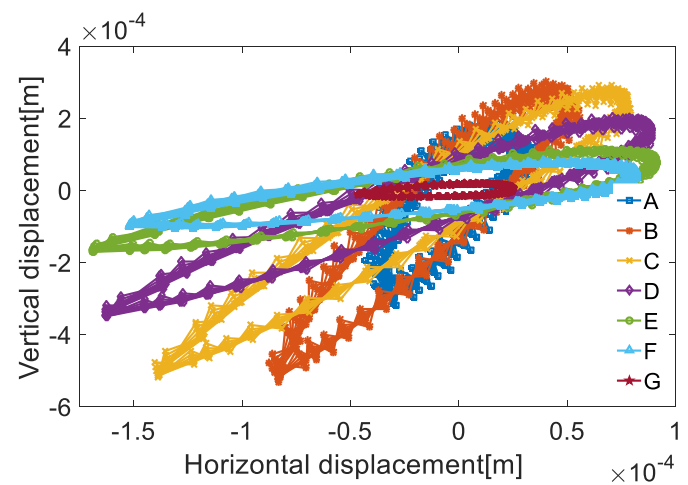

(b)

Fig.23 Trajectories of shaft sections considering the thermal-mechanical coupling effect: (a) no-load, (b) blanking It can be observed from Fig. 22 that the maximum vertical vibration displacement under noload condition considering the thermal-mechanical coupling effect occurs on the shaft sections 15 , 17 , the corresponding amplitude of which is $2.1 \times 10^{-5} \mathrm{~m}$, while the minimum vertical vibration displacement exists on the shaft sections 1 and 4 that are far away from the eccentric shaft section. The maximum vertical vibration displacement under blanking condition are located on the shaft segments 4,7 and the corresponding amplitude is $5.1 \times 10^{-4} \mathrm{~m}$. Figure 23 shows that the vibration amplitude of each shaft section under blanking condition is larger than that under no-load condition. Furthermore, the zigzag shapes of the shaft centre trajectories are significant due to the thermal expansion of ACBBs and the eccentric mass of the synchronous pulley. 


\section{Model validation and results discussion}

The position accuracy of slider's BDP for MHSPP is mainly affected by the transmission errors of multilink mechanism and the crankshaft-bearing structure. As shown in Fig. 2, the dimension chain of the flexible planar multilink mechanism with clearance and crankshaft-bearing structure can be given by

$$
L_{S B}(t)=L_{B C}(t)+L_{S C}(t)
$$

Where $L_{S B}(t), L_{B C}(t)$ and $L_{S C}(t)$ are the actual dimension between the slider and bearing support centre, bearing support centre and shaft centre, slider and shaft centre, respectively.

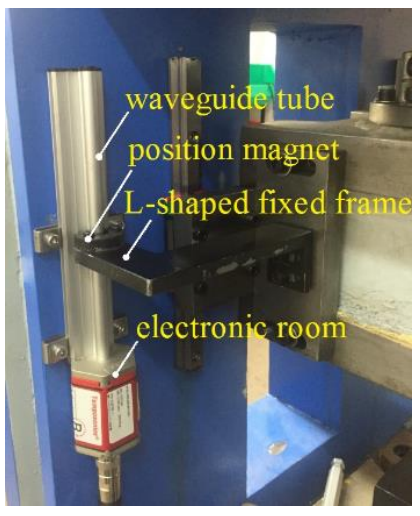

(a)

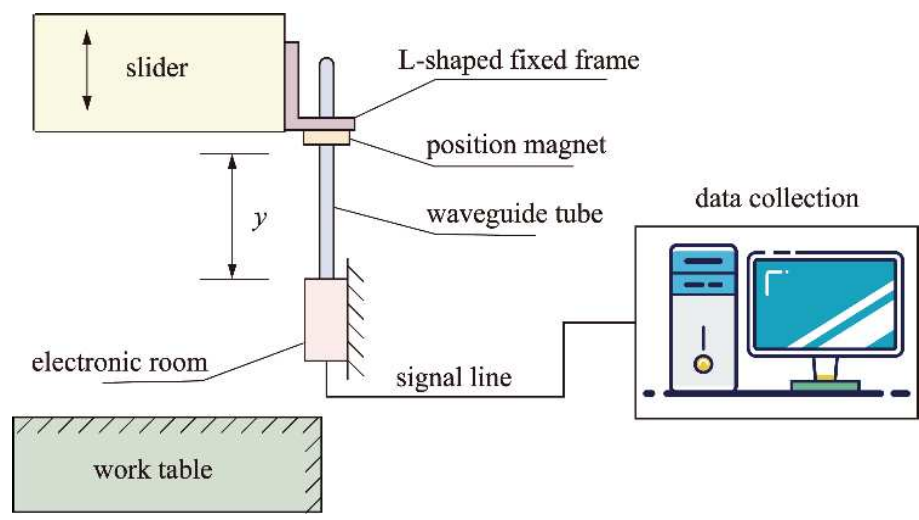

(b)

Fig.24 Dynamic test system of slider for the multilink mechanism: (a) experiment platform, (b) test principle

Table 3 Parameters of flexible multilink mechanism with clearance

\begin{tabular}{|c|c|c|c|}
\hline Parameters & Value & Parameters & Value \\
\hline Eccentric distance of crank shaft $l_{2} /(\mathrm{m})$ & 0.0178 & Length of link $5 l_{5} /(\mathrm{m})$ & 0.1075 \\
\hline Mass of crank shaft $m_{2} /(\mathrm{kg})$ & 17.3 & Mass of link $5 m_{5} /(\mathrm{kg})$ & 3.12 \\
\hline Rotary inertia of crank shaft $J_{2} /\left(\mathrm{kg} \cdot \mathrm{m}^{2}\right)$ & 0.0174 & Rotary inertia of link $5 J_{5} /\left(\mathrm{kg} \cdot \mathrm{m}^{2}\right)$ & 0.0174 \\
\hline Length of link $3 l_{3} /(\mathrm{m})$ & 0.1965 & Length of link $6 l_{6} /(\mathrm{m})$ & 0.1075 \\
\hline Rotary inertia of link $3 J_{3} /\left(\mathrm{kg} \cdot \mathrm{m}^{2}\right)$ & 0.0351 & Rotary inertia of link $6 J_{6} /\left(\mathrm{kg} \cdot \mathrm{m}^{2}\right)$ & 0.0599 \\
\hline Mass of slider $4 m_{4} /(\mathrm{kg})$ & 6.42 & Mass of slider $7 m_{7} /(\mathrm{kg})$ & 121.43 \\
\hline Mass of slider $8 m_{8} /(\mathrm{kg})$ & 107.05 & Supremum of tangent velocity $v_{u} /(\mathrm{mm} / \mathrm{s})$ & 50 \\
\hline Pin radius between link 7 and slider $8 R_{P} /(\mathrm{m})$ & 0.07 & Number of flexible linkage elements & 4 \\
\hline Coefficient of restitution $c_{e}$ & 0.9 & Poisson's ratio of pin $\mu_{P}$ & 0.29 \\
\hline Poisson's ratio of bushing $\mu_{B}$ & 0.38 & Young's modulus of bushing $E_{B} /(\mathrm{GPa})$ & 0.5 \\
\hline Young's modulus of pin $E_{P} /(\mathrm{GPa})$ & 206.8 & Coefficient of friction $c_{f}$ & 0.01 \\
\hline Density of linkage $\rho_{l} /\left(\mathrm{kg} / \mathrm{m}^{2}\right)$ & 7800 & Young's modulus of linkage $E_{l} /\left(\mathrm{N} / \mathrm{m}^{2}\right)$ & $2.1 \times 10^{11}$ \\
\hline Cross sectional area of linkage $A_{l} /\left(\mathrm{m}^{2}\right)$ & 0.0027 & Diametral inertia moment of linkage $I_{l} /\left(\mathrm{m}^{4}\right)$ & $2.25 \times 10^{-6}$ \\
\hline Pulse width of punching force $\tau /(\mathrm{s})$ & 0.00417 & Maximum punching force $F_{\max } /(\mathrm{kN})$ & 10 \\
\hline
\end{tabular}

In order to verify the effectiveness of the improved model, the dynamic responses of slider

for the multilink mechanism are measured, based on the experimental platform of multilink mechanism shown in Fig. 24(a). The dynamic test system of slider for the multilink mechanism, is 
mainly composed of position magnet, L-shaped fixed frame, waveguide and electronic chamber (strain pulse detector). Figure 24(b) demonstrates the principle behind the test, specifically speaking, one end of the L-shaped bracket is fixed on the main slider and the other end is connected with the position magnet to ensure the mutual position relationship between the position magnet and the waveguide. In the process of sliding block movement, the position magnet can realize synchronous up and down movement along the waveguide by relying on the L-shaped bracket. The position magnet in the magnetostrictive displacement sensor and the waveguide will generate two intersecting magnetic fields under operation condition. When the position magnet is relatively displaced along the waveguide, the change of the intersecting magnetic field will produce a strain mechanical wave pulse signal in the waveguide tube, which will be directly detected by the electronic chamber. Since the distance between the active magnetic ring and the electronic chamber is proportional to the transmission time, the position of the active magnetic ring can be determined with high precision by measuring the transmission time. The position signal is stored by the data acquisition card and displayed online. Due to the sensor itself and the interference of the current signal in the transmission process, the actual measured slider position signal is often corrupted by noise. To solve it, EMI hardware and digital smoothing filtering method are applied to improve the measurement accuracy.

The parameters of flexible multilink mechanism with clearance are listed in Table 3 . When setting the crankshaft speed, punching force, contact angle and clearance size as $200 \mathrm{rpm}, 10 \mathrm{kN}$, $40^{\circ}$ and $0.1 \mathrm{~mm}$, respectively, the simulated and experimental position errors of slider's BDP under no-load and blanking conditions with/without the thermal-mechanical coupling effect of the crankshaft-bearing structure considered are shown in Fig. 25.

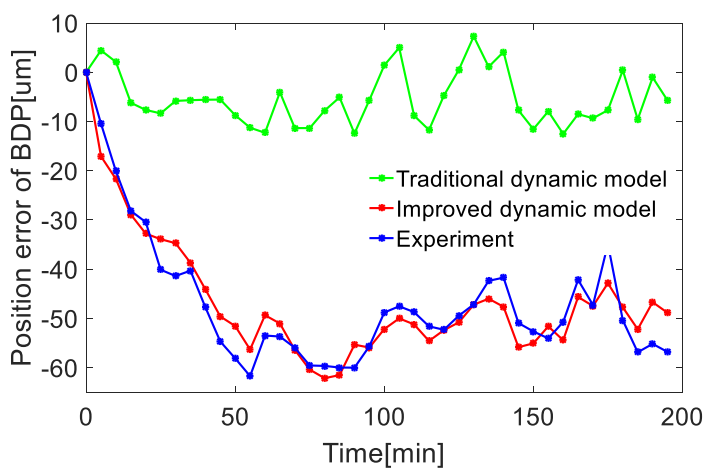

(a)

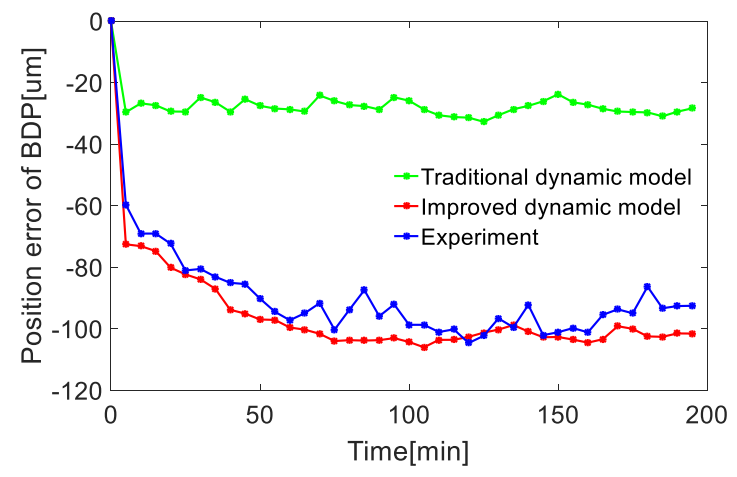

(b)

Fig.25 Simulated and experimental position errors of slider's BDP: (a) no-load, (b) blanking

Figure 25 shows that the position error of slider's BDP for MHSPP initially increases tremendously and then fluctuates around a stable value. Compared to that neglecting the thermalmechanical coupling effect of the crankshaft-bearing structure, the simulated position error of slider's BDP considering the thermal-mechanical coupling effect of the crankshaft-bearing system agrees better with experimental data and the validity of the improved model is verified. The stable position deviation of slider's BDP for MHSPP under no-load condition is about $-50 \mu \mathrm{m}$, while that under blanking condition fluctuates around $-100 \mu \mathrm{m}$. The position deviation of slider's BDP under no-load and blanking conditions considering the thermal-mechanical coupling effect of the crankshaft-bearing structure is larger than that neglecting the thermal-mechanical coupling effect. 
Therefore, the punching force and thermally induced variable stiffness of bearing increase the position deviation of slider's BDP significantly and reduce the dynamic accuracy of MHSPP.

\subsection{Influence of crankshaft speed on position error of slider's BDP}

When the punching force, contact angle and clearance size are set as $10 \mathrm{kN}, 40^{\circ}$ and $0.1 \mathrm{~mm}$, respectively, the position errors of slider's BDP under different crankshaft speeds considering the thermal-mechanical coupling effect of the crankshaft-bearing structure are shown in Fig. 26.

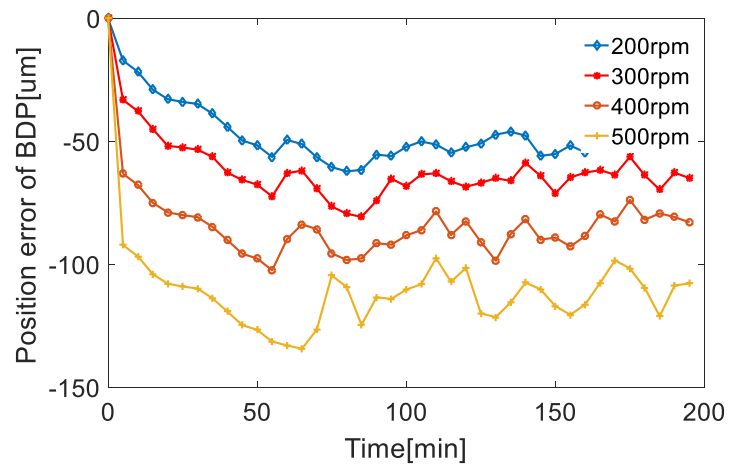

(a)

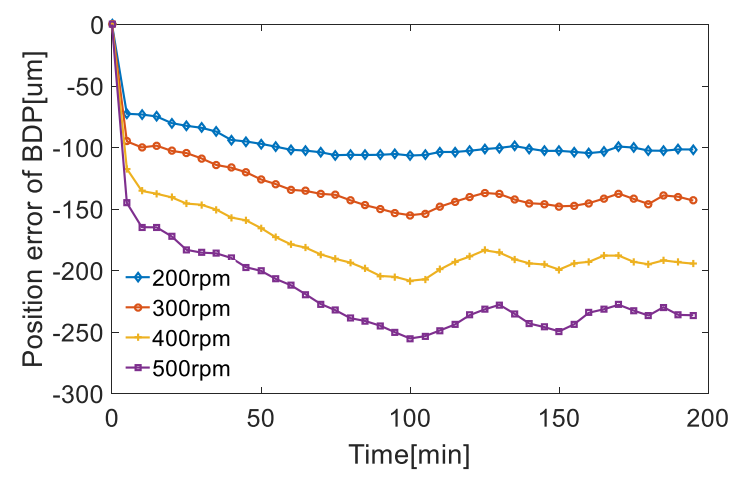

(b)

Fig.26 Position errors of slider's BDP under different crankshaft speeds: (a) no load, (b) blanking

It can be observed in Fig. 26 that the position error and fluctuation amplitude rise significantly with the increase of crankshaft speed. When the crankshaft speed increases from 200 $\mathrm{rpm}$ to $500 \mathrm{rpm}$, the times for stable position error of slider's BDP under no-load condition are 55 min, $56 \mathrm{~min}, 56 \mathrm{~min}$ and $60 \mathrm{~min}$ respectively, and the corresponding stable position errors of slider's BDP are $-50 \mu \mathrm{m},-70 \mu \mathrm{m},-90 \mu \mathrm{m}$ and $-120 \mu \mathrm{m}$, respectively. The times for stable position error of slider's BDP under blanking condition are $95 \mathrm{~min}, 100 \mathrm{~min}, 100 \mathrm{~min}$ and $100 \mathrm{~min}$ respectively, and the corresponding stable position errors of slider's BDP are -100 $\mu \mathrm{m},-140 \mu \mathrm{m}$, $180 \mu \mathrm{m}$ and $-240 \mu \mathrm{m}$, respectively. Therefore, the stable time of slider's BDP position error is not sensitive to the crankshaft speed. The punching force can increase the position error of slider's BDP, while reduces the fluctuation amplitude of slider's BDP position error.

\subsection{Influence of contact angle on position error of slider's BDP}

When the crankshaft speed, punching force and clearance size are $200 \mathrm{rpm}, 10 \mathrm{kN}$ and 0.1 $\mathrm{mm}$, respectively, the position errors of slider's BDP under different contact angles considering the thermal-mechanical coupling effect of the crankshaft-bearing structure are shown in Fig. 27.

Figure 27 shows that the position error of slider's BDP decreases initially and then rises with the increase of contact angle. When the contact angle increases from $15^{\circ}$ to $60^{\circ}$, the times for stable position error of slider's BDP under no-load condition are $50 \mathrm{~min}, 30 \mathrm{~min}, 55 \mathrm{~min}$ and 50 $\mathrm{min}$, respectively, and the corresponding stable position errors of slider's BDP are $-40 \mu \mathrm{m},-20 \mu \mathrm{m}$, $-50 \mu \mathrm{m}$ and $-70 \mu \mathrm{m}$, respectively. The times for stable position error of slider's BDP under blanking condition are $90 \mathrm{~min}, 80 \mathrm{~min}, 80 \mathrm{~min}$ and $85 \mathrm{~min}$, respectively, and the corresponding stable position errors of slider's BDP are $-70 \mu \mathrm{m},-40 \mu \mathrm{m},-100 \mu \mathrm{m}$ and $-140 \mu \mathrm{m}$, respectively. It's demonstrated that the optimized contact angle is $25^{\circ}$, which can increase the position accuracy of 
slider's BDP and reduce the fluctuation amplitude of slider's BDP position error.

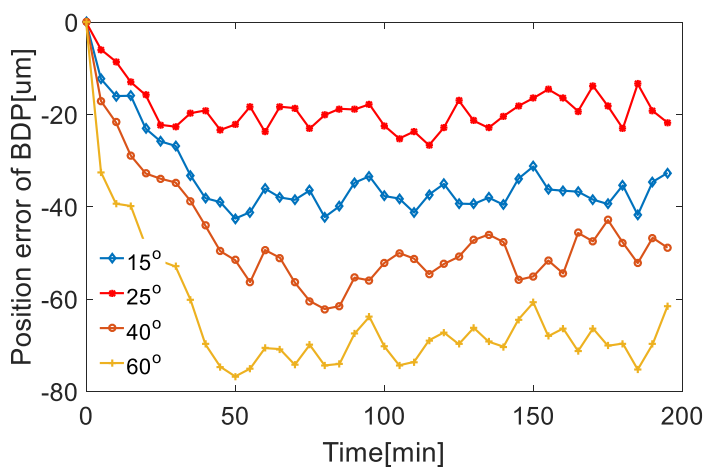

(a)

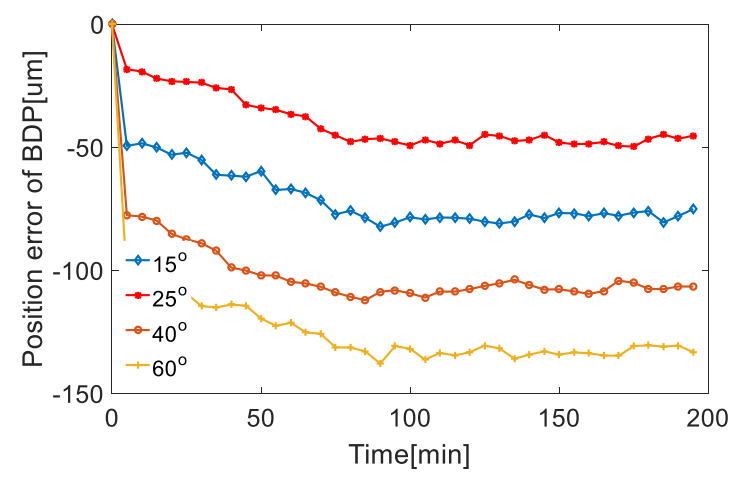

(b)

Fig.27 Position errors of slider's BDP under different contact angles: (a) no load, (b) blanking

\subsection{Influence of clearance size on position error of slider's BDP}

When the crankshaft speed, punching force and contact angle are $200 \mathrm{rpm}, 10 \mathrm{kN}$ and $40^{\circ}$, respectively, the position errors of slider's BDP under different clearance sizes considering the thermal-mechanical coupling effect of the crankshaft-bearing structure are shown in Fig. 28.

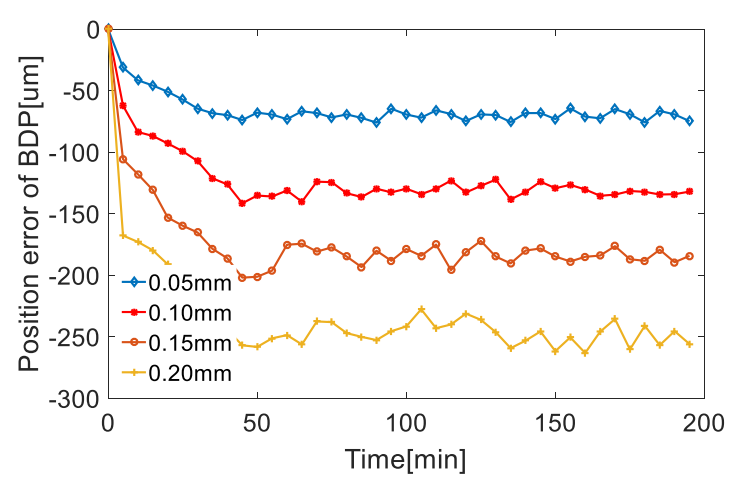

(a)

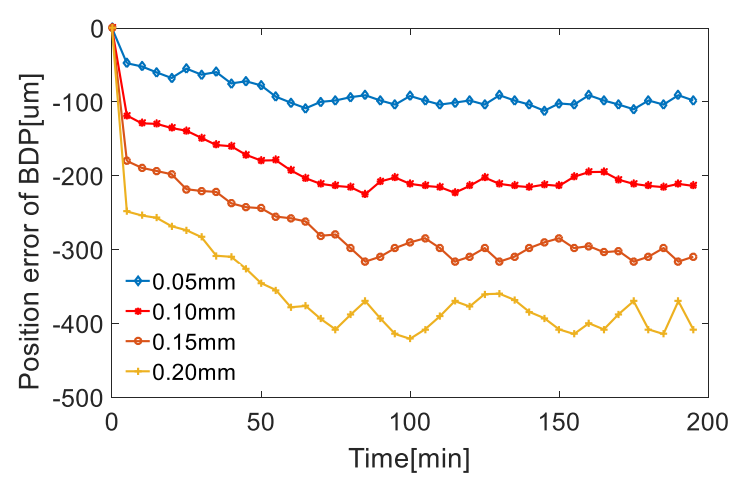

(b)

Fig.28 Position errors of slider's BDP under different clearance sizes: (a) no load, (b) blanking

Figure 28 shows the position error of slider's BDP rises significantly with the increase of clearance size. When the clearance size increases from $0.05 \mathrm{~mm}$ to $0.2 \mathrm{~mm}$, the times for stable position error of slider's BDP under no-load condition are $50 \mathrm{~min}, 50 \mathrm{~min}, 50 \mathrm{~min}$ and $45 \mathrm{~min}$, respectively, and the corresponding stable position errors of slider's BDP are $-60 \mu \mathrm{m},-130 \mu \mathrm{m}$, $190 \mu \mathrm{m}$ and $-250 \mu \mathrm{m}$, respectively. The times for stable position error of slider's BDP under blanking condition are $70 \mathrm{~min}, 80 \mathrm{~min}, 80 \mathrm{~min}$ and $75 \mathrm{~min}$ respectively, and the corresponding stable position errors of slider's BDP are $-100 \mu \mathrm{m},-200 \mu \mathrm{m},-300 \mu \mathrm{m}$ and $-400 \mu \mathrm{m}$, respectively. It's inferred that the stable time of slider's BDP position error is not sensitive to the clearance size.

\section{Conclusion}

(1) TNM of the crankshaft-bearing system is established considering the effects of thermal contact resistance and variable stiffness of bearing concerning temperature rise and the effectiveness of the developed TNM is verified through experiment. The simulation results show 
that the maximum temperature rise of the crankshaft-bearing system is concentrated on the nodes near the rolling elements of bearing and the corresponding average temperature rise reaches $25{ }^{\circ} \mathrm{C}$, while the average temperature rise of the remaining nodes is only $5{ }^{0} \mathrm{C}$.

(2) Thermal-mechanical coupling model of the crankshaft-bearing system is built. The preload of ACBB is increased significantly, while the radial stiffness is reduced as a result of bearing's thermal expansion. The vibration amplitude of each shaft section under blanking condition is larger than that under no-load condition and the zigzag shapes of the shaft centre trajectories are obvious due to the thermal expansion of ACBBs and the eccentric mass of the synchronous pulley.

(3) An improved dynamic model of planar flexible multilink mechanism with clearance considering the thermal-mechanical coupling effect of the crankshaft-bearing structure is developed and the corresponding dynamic error dimension chain between slider and crankshaft is constructed. The simulated position error of slider's BDP considering the thermal-mechanical coupling effect of the crankshaft-bearing system fits better with experimental data than that neglecting the thermal characteristics of the crankshaft-bearing structure, which proves the correctness of the proposed model.

(4) The punching force and thermally induced variable stiffness of ACBB increase the position error of the slider's BDP significantly and reduce the dynamic accuracy of MHSPP. The position error and fluctuation amplitude rise significantly with the increase of crankshaft speed and clearance size, while the stable time of slider's BDP position error is not sensitive to the crankshaft speed and clearance size. The position error of slider's BDP decreases initially and then rises with the increase of contact angle, and the optimized contact angle is $25^{\circ}$.

\section{Conflicts of Interest}

The authors declare that they have no known competing financial interests or personal relationships that could have appeared in this work.

\section{Acknowledgment}

This work was supported by the following research projects: National Natural Science Foundation of China (Grant numbers 52075269 and 51405238), The Fundamental Research Funds for the Central Universities (Grant number KYTZ201603), The Innovation Fund of Science and Technology for Outstanding Youth from College of Engineering, Nanjing Agricultural University (Grant number YQ201606), and Qing Lan Project of Jiangsu Province (Grant number 80400103). The authors would like to express their appreciation to the agencies.

\section{Availability of Data}

The datasets used or analyzed during the current study are available from the corresponding author on reasonable request. 


\section{References}

1. Lv, T.Q., Zhang, Y.Q., Duan, Y.P., Yang, J.: Kinematics \& compliance analysis of double wishbone air suspension with frictions and joint clearances. Mech Mach Theory. 156, 1-26 (2021)

2. Zheng, X.D., Li, J., Wang, Q., Liao, Q.M.: A methodology for modeling and simulating frictional translational clearance joint in multibody systems including a flexible slider part. Mech Mach Theory. 142, 1-14 (2019)

3. Tan, H.Y., Hu, Y.J., Li, L.: Effect of friction on the dynamic analysis of slider-crank mechanism with clearance joint. Int J Non Linear Mech. 115, 20-40 (2019)

4. Lai, X.M., Lai, Q.F., Huang, H., Wang, C., Yang, J.H., Zhang, Y.: New approach to assess and rank the impact of revolute joint wear on the kinematic accuracy in the low-velocity planar mechanism. Adv Eng Softw. 102, 71-82 (2016)

5. Zhang, H.B., Chen, Z.K., Wei, C., Zhao, Y., You, B.D.: Vibration characteristics analysis of aerospace mechanism transmission joints considering multiple clearances. Chin J Mech Eng. 53(11), 44-53 (2017)

6. Xiao, H., Yang, Q.L., Ren, S.Z., Li, L., Xu, K., Ding, X.L.: Design analysis and stiffness test research on joints of large socket-type spreading and retracting mechanism. J Mech Des, Trans ASME. 54(7), 1-10 (2018)

7. Skrinjar, L., Slavic, J., Boltezar, M.: A review of continuous contact-force models in multibody dynamics. Int J Mech Sci. 145, 171-187 (2018)

8. Lankarani, H.M., Nikravesh, P.E.: A contact force model with hysteresis damping for impact analysis of multibody systems. J Mech Des, Trans ASME. 112(3), 369-376 (1990)

9. Flores, P., Machado, M., Silva, M.T., Martins, J.M.: On the continuous contact force models for soft materials in multibody dynamics. Multibody Syst Dyn. 25(3), 357-375 (2011)

10. Hu, S.W., Guo, X.L.: A dissipative contact force model for impact analysis in multibody dynamics. Multibody Syst Dyn. 35(2), 131-151 (2015)

11. Li, Y.Y., Chen, G.P., Sun, D.Y., Gao, Y., Wang, K.: Dynamic analysis and optimization design of a planar slider-crank mechanism with flexible components and two clearance joints. Mech Mach Theory. 99, 37-57 (2016)

12. Zhao, B., Dai, X.D., Zhang, Z.N., Xie, Y.B.: Numerical study of the effects on clearance joint wear in flexible multibody mechanical systems. J Tribol. 58(3), 385-396 (2015)

13. Pennestri, E., Rossi, V., Salvini, P., Valentini, P.P.: Review and comparison of dry friction force models. Nonlinear Dyn. 83(4), 1785-1801 (2016)

14. Koshy, C.S., Flores, P., Lankarani, H.M.: Study of the effect of contact force model on the dynamic response of mechanical systems with dry clearance joints: computational and experimental approaches. Nonlinear Dyn. 73(1-2), 325-338 (2013)

15. Gummer, A., Sauer, B.: Modeling planar slider-crank mechanisms with clearance joints in RecurDyn. Multibody Syst Dyn. 31(2), 127-145 (2014)

16. Piatkowski, T.: Dahl and LuGre dynamic friction models-The analysis of selected properties. Mech Mach Theory. 73, 91-100 (2014) 
17. Marques, F., Flores, P., Claro, J.C.P., Lankarani, H.M.: A survey and comparison of several friction force models for dynamic analysis of multibody mechanical systems. Nonlinear Dyn. 86(3), 1407-1443 (2016)

18. Jin, X.L., Wang, Y., Huang, Z.L.: Approximately analytical technique for random response of LuGre friction system. Int J Non Linear Mech. 104, 1-7 (2018)

19. Wang, X.P., Liu, G., Ma, S.J., Tong, R.T.: Study on dynamic responses of planar multibody systems with dry revolute clearance joint: numerical and experimental approaches. J Sound Vib. 438, 116-138 (2019)

20. Wang, Z., Tian, Q., Hu, H.Y., Flores, P.: Nonlinear dynamics and chaotic control of a flexible multibody system with uncertain joint clearance. Nonlinear Dyn. 86(3), 1571-1597 (2016)

21. Wang, G.X., Liu, H.Z.: Dynamic analysis and wear prediction of planar five-bar mechanism considering multi-flexible links and multi-clearance joints. J. Tribol. 139(5), 1-14 (2017)

22. Zheng, E.L., Zhou, X.L.: Modeling and simulation of flexible slider-crank mechanism with clearance for a closed high speed press system. Mech Mach Theory. 74, 10-30 (2014)

23. Zheng, E.L., Zhu, R., Zhu, S.H., Lu, X.J.: A study on dynamics of flexible multi-link mechanism including joints with clearance and lubrication for ultra-precision presses. Nonlinear Dyn. 83, 137-159 (2016)

24. Zheng, E.L., Wang, T.Y., Guo, J., Zhu, Y., Lin, X.Z., Wang, Y.J., Kang, M.: Dynamic modeling and error analysis of planar flexible multilink mechanism with clearance and spindle-bearing structure. Mech Mach Theory. 131, 234-260 (2019)

25. Aleyaasin, M., Ebrahimi, M., Whalley, R.: Vibration analysis of distributed-lumped rotor systems. Comput Methods Appl Mech Eng. 189(2), 545-558 (2000)

26. Hsieh, S.C., Chen, J.H., Lee, A.C.: A modified transfer matrix method for the coupling lateral and torsional vibrations of symmetric rotor-bearing systems. J Sound Vib. 289(1), 294-333 (2006)

27. Jiang, S.Y., Zheng, S.F.: A modeling approach for analysis and improvement of spindledrawbar-bearing assembly dynamics. Int J Mach Tools Manuf. 50(1), 131-142 (2010)

28. Jiang, S.Y., Zheng, S.F.: Dynamic design of a high-speed motorized spindle-bearing system. J Mech Des, Trans ASME. 132(3), 34501-34505 (2010)

29. Booker, J.F., Ruhl, R.L.: A finite element model for distributed parameter turborotor systems. J. Eng. Technol. 94(1), 126-132 (1972)

30. Aini, R., Rahnejat, H., Gohar, R.: A five degrees of freedom analysis of vibrations in precision spindles. Int J Mach Tools Manuf. 30(1), 1-18 (1990)

31. Sinou, J.J.: Non-linear dynamics and contacts of an unbalanced flexible rotor supported on ball bearings. Mech Mach Theory. 44(9), 1713-1732 (2009)

32. Nelson, H.D.: A finite rotating shaft element using Timoshenko beam theory. J Mech Des, Trans ASME. 102(4), 793-803 (1980)

33. Wang, L., Jia, F., Chen, S.X., Wang, X.S.: Dynamics of a high-speed press rotor-bearing system. J Vib Eng. 25(4), 460-466 (2012)

34. Chen, X.A., Liu, J.F.: Thermal properties of high speed motorized spindle and their effects. J Mech Des, Trans ASME. 11, 135-142 (2013) 
35. Yan, B., Yan, K., Luo, T., Zhu, Y.S., Li, B.Q., Hong, J.: Thermal coefficients modification of high speed ball bearing by multi-object optimization method. Int J Therm Sci. 137, 313-324 (2019)

36. Zhang, Y.F., Li, X.H., Hong, J., Yan, K., Li, S.: Uneven heat generation and thermal performance of spindle bearings. Tribol Int. 126, 324-335 (2018)

37. Zheng, E.L., Jia, F., Zhu, S.H.: Thermal modeling and characteristics analysis of the high speed press system. Int J Mach Tools Manuf. 85, 87-99 (2014)

38. Zheng, E.L., Yang, Y.Z., Peng, Z.H., Zhu, Y., Zhao, X., Lin, X.Z., Kang, M.: Thermal characteristics analysis and error prediction for lubricated multi-link high speed precision presses. J. Mech. Sci. Technol. 33(6), 1-23 (2019)

39. Zheng, E.L., Xie, S.L., Zhang, J., Zhu, Y., Zhao, X., Lin, X.Z., Kang, M.: An improved thermal model for characteristics analysis of multi-link ultra-precision press system. J. Mech. Sci. Technol. 32(1), 1-23 (2018)

40. Liu, J.F., Chen, X.A.: Dynamic design for motorized spindles based on an integrated model. The Int J Adv Manuf Technol. 71, 9-12 (2014)

41. Zahedi, A., Movahhedy, M.R.: Thermo-mechanical modeling of high speed spindles. Sci. Iran B. 19(2), 282-293 (2012)

42. Lai, T., Liu, J.F., Tie, G.P.: Influence of thermo-mechanical coupled behaviors on milling stability of high speed motorized spindles. Precis Eng. 52, 94-105 (2018)

43. Truong, D.S., Kim, B.S., Ro, S.K.: An analysis of a thermally affected high-speed spindle with angular contact ball bearings. Tribol Int. 157, 106881 (2021)

44. Ma, C., Yang, J., Zhao, L., Mei, X.S., Shi, H.: Simulation and experimental study on the thermally induced deformations of high-speed spindle system. Appl Therm Eng. 86, 251-268 (2015)

45. Cao, Y.Z., Altintas, Y.: A general method for the modeling of spindle-bearing systems, J Mech Des. Trans ASME. 126(6), 1089-1104 (2004)

46. Than, V.T., Huang, J.H.: Nonlinear thermal effects on high-speed spindle bearings subjected to preload. Tribol Int. 96, 361-372 (2016) 


\section{The list of table captions:}

Table 1 Dynamic simulation parameters of the crankshaft-bearing system

Table 2 Parameters of TNM for the crankshaft-bearing system

Table 3 Parameters of flexible multilink mechanism with clearance

\section{The list of figure captions:}

Fig.1. Solid model of multilink mechanism

Fig.2. Multibody dynamic model of multilink mechanism

Fig.3. Model of revolute clearance joint

Fig.4. Model of flexible linkage

Fig.5. Structure of the crankshaft-bearing system for MHSPP

Fig.6. FE model of the crankshaft-bearing system

Fig.7. Geometry relationship of the ACBB

Fig.8. Displacement relationship between inner and outer curvature centres

Fig.9. Force balance of rolling element

Fig.10. Blanking force

Fig.11. Vertical displacement of the crankshaft sections neglecting the thermal effect: (a) no-load, (b) blanking

Fig.12 Trajectories of the crankshaft sections neglecting the thermal effect: (a) no-load, (b) blanking

Fig.13 TNM of the crankshaft-bearing coupling system

Fig.14. Energy transfer relationship of thermal network nodes

Fig.15. Temperature rise of four bearings under no-load condition: (a) No.2, (b) No.3, (c) No.4, (d) No.5

Fig.16. Steady-state temperature distribution of the crankshaft-bearing system: (a) no-load, (b) blanking

Fig.17. Temperature rise variation of network nodes for the crankshaft-bearing system: (a) no load, (b) blanking

Fig.18. Preload of the ACBB under positioning mode

Fig.19. Geometric relationship of ACBBs considering the thermal-mechanical coupling effect

Fig.20. Preload and radial stiffness of ACBB considering the effect of thermal expansion: (a) 
preload, (b) radial stiffness

Fig.21. Dynamic simulation flow chart of crankshaft-bearing system considering the thermalmechanical coupling effect

Fig.22. Vertical displacement of shaft sections considering the thermal-mechanical coupling effect: (a) no-load, (b) blanking

Fig.23. Trajectories of shaft sections considering the thermal-mechanical coupling effect: (a) noload, (b) blanking

Fig.24. Dynamic test system of slider for the multilink mechanism: (a) experiment platform, (b) test principle

Fig.25. Simulated and experimental position errors of slider's BDP: (a) no-load, (b) blanking

Fig.26. Position errors of slider's BDP under different crankshaft speeds: (a) no load, (b) blanking

Fig.27. Position errors of slider's BDP under different contact angles: (a) no load, (b) blanking

Fig.28. Position errors of slider's BDP under different clearance sizes: (a) no load, (b) blanking 